\title{
Evaluation of standard imaging techniques and volumetric preservation of nervous tissue in genetically identical offspring of the crayfish Procambarus fallax cf. virginalis (Marmorkrebs)
}

\author{
Emanuel S Nischik ${ }^{1}$, Jakob Krieger ${ }^{\text {Corresp. } 1}$ \\ ${ }^{1}$ Zoological Institute and Museum, Cytology and Evolutionary Biology, University of Greifswald, Greifswald, Germany \\ Corresponding Author: Jakob Krieger \\ Email address: jakob.krieger@uni-greifswald.de
}

In the field of comparative neuroanatomy, a meaningful interspecific comparison demands quantitative data referring to method-specific artifacts. For evaluating the potential of state-of-the-art imaging techniques in arthropod neuroanatomy, micro-computed X-ray microscopy $(\mu \mathrm{CT})$ and two different approaches using confocal laser-scanning microscopy (cLSM) were applied to obtain volumetric data of the brain and selected neuropils in Procambarus fallax forma virginalis (Crustacea, Malacostraca, Decapoda). The marbled crayfish $P$. fallax cf. virginalis features a parthogenetic reproduction generating genetically identical offspring from unfertilized eggs. Therefore, the studied organism provides ideal conditions for the comparative analysis of neuroanatomical imaging techniques and the effect of preceding sample preparations of nervous tissue. We found that wet scanning of whole animals, conducted with $\mu \mathrm{CT}$ turned out to be the least disruptive method. However, in an additional experiment it was discovered that fixation in Bouin's solution, required for $\mu C T$ scans, resulted in an average tissue shrinkage of $24 \%$ compared to freshly dissected and unfixed brains. The complete sample preparation using fixation in half-strength Karnovsky's solution of dissected brains led to an additional volume decrease of $12.5 \%$, whereas the preparation using zinc-formaldehyde as fixative resulted in a shrinkage of $5 \%$ in comparison to the volumes obtained by $\mu \mathrm{CT}$. By minimizing individual variability, at least for aquatic arthropods, this pioneer study aims for the inference of method-based conversion factors in the future, providing a valuable tool for reducing quantitative neuroanatomical data already published to a common denominator. However, volumetric deviations could be shown for all experimental protocols due to methodological noise and/or phenotypic plasticity among genetically identical individuals. Micro-computed X-ray microscopy using undried tissue is an appropriate non-disruptive technique for allometry of arthropod brains since spatial organ relationships are conserved and tissue shrinkage is minimized. Collecting tissue-based shrinkage factors according to specific sample 
preparations might allow a better comparability of volumetric data from the literature, even if another technique was applied. 
1 Evaluation of standard imaging techniques and volumetric preservation of

2 nervous tissue in genetically identical offspring of the crayfish Procambarus

3 fallax cf. virginalis (Marmorkrebs)

4

5

6 EMANUEl SET NischiK ${ }^{1}$ AND JAKOB KRIEGER ${ }^{1 *}$

$7 \quad{ }^{1}$ University of Greifswald, Zoological Institute and Museum, Cytology and Evolutionary

8 Biology, Soldmannstraße 23, 17489 Greifswald

9 Contact: en122971@uni-greifswald.de; jakob.krieger@uni-greifswald.de

10

11 * corresponding author

12

13

14

15

16

17

18

19

20

21

22

23

24 


\section{Abstract}

26 In the field of comparative neuroanatomy, a meaningful interspecific comparison demands quantitative data referring to method-specific artifacts. For evaluating the potential of state-ofthe-art imaging techniques in arthropod neuroanatomy, micro-computed X-ray microscopy $(\mu \mathrm{CT})$ and two different approaches using confocal laser-scanning microscopy (cLSM) were applied to obtain volumetric data of the brain and selected neuropils in Procambarus fallax forma virginalis (Crustacea, Malacostraca, Decapoda). The marbled crayfish P. fallax cf. virginalis features a parthogenetic reproduction generating genetically identical offspring from unfertilized eggs. Therefore, the studied organism provides ideal conditions for the comparative analysis of neuroanatomical imaging techniques and the effect of preceding sample preparations of nervous tissue.

We found that wet scanning of whole animals, conducted with $\mu \mathrm{CT}$ turned out to be the least disruptive method. However, in an additional experiment it was discovered that fixation in Bouin's solution, required for $\mu \mathrm{CT}$ scans, resulted in an average tissue shrinkage of $24 \%$ compared to freshly dissected and unfixed brains. The complete sample preparation using fixation in half-strength Karnovsky's solution of dissected brains led to an additional volume decrease of $12.5 \%$, whereas the preparation using zinc-formaldehyde as fixative resulted in a shrinkage of $5 \%$ in comparison to the volumes obtained by $\mu \mathrm{CT}$. By minimizing individual variability, at least for aquatic arthropods, this pioneer study aims for the inference of methodbased conversion factors in the future, providing a valuable tool for reducing quantitative neuroanatomical data already published to a common denominator. However, volumetric deviations could be shown for all experimental protocols due to methodological noise and/or phenotypic plasticity among genetically identical individuals.

Micro-computed X-ray microscopy using undried tissue is an appropriate non-disruptive technique for allometry of arthropod brains since spatial organ relationships are conserved and tissue shrinkage is minimized. Collecting tissue-based shrinkage factors according to specific sample preparations might allow a better comparability of volumetric data from the literature, even if another technique was applied.

\section{Introduction}


55 Micro-computed X-ray tomography and three-dimensional reconstruction of internal

56 morphological structures have opened up new possibilities for analyzing the anatomy of nervous

57 systems in intact specimens (reviewed in Metscher, 2009; Sombke et al., 2015). In addition to

58 vertebrates, the application of X-ray microscopy of soft tissues has been demonstrated to be

59 useful for a variety of metazoan taxa, such as cnidarians (e.g. Holst et al., 2016), nematomorphs

60 (Henne et al., 2016), nematodes (O’Sullivan et al., 2017), polychaetes (e.g. Dinley et al., 2010;

61 Faulwetter et al., 2013), mollusks (e.g. Handschuh et al., 2013), as well as arthropods (e.g.

62 Akkari et al., 2015; Michalik et al., 2013; Sombke et al., 2015; Steinhoff et al., 2017).

63 Whole-mount scanning using confocal laser-scanning microscopy (Krieger et al., 2015; Ott \&

64 Elphick, 2003; Ott, 2008) and especially micro-computed X-ray microscopy are suitable

65

66

67

68

69

70

71

72

methods for precisely capturing three-dimensional structures without the need of histological sections. In samples with various tissue structures densely packed together, most imaging techniques require elaborate contrasting- or staining procedures (Metscher, 2009). In most cases, the tissue must be fixed and dehydrated in advance. The fixation process ideally fulfills the function of counteracting the structural and morphological changes induced by decay, which begins immediately after death of an organism (Lang, 2013). The chosen fixative and its time of penetration, subsequent preparation and imaging technique crucially influence the preservation of the tissue's spatial morphology on which the accuracy of allometric analysis essentially depends. Ethanolic and aldehydic solutions containing formaldehyde (or its polymer paraformaldehyde) or glutaraldehyde are the most widely used chemical fixatives in histology. Aldehydic fixatives protect proteins against denaturation by cross-linking them. No fixative preserves all structures alike, thus usually mixtures are applied (e.g. Bouin or Karnovsky) to compensate adverse effects of single components. Obviously, the preparation should aim to maintain an isotonic milieu for tissue preservation (reviewed in Lang, 2013). For microcomputed X-ray microscopy, contrast-enhancing, especially for the visualization of soft tissues (Gignac et al., 2016; Holst et al., 2016; Metscher, 2009; Mizutani \& Suzuki, 2012), is usually realized by increasing adsorption of X-rays applying solutions containing iodine $\left(\mathrm{I}_{2}\right)$, osmium tetroxide $\left(\mathrm{OsO}_{4}\right)$, or phosphotungstic acid $\left(\mathrm{H}_{3} \mathrm{PW}_{12} \mathrm{O}_{40}\right)$ as was demonstrated by Metscher (2009). The sample manipulation in preparation for tomographic imaging for both confocal laser-scanning microscopy as well as micro-computed X-ray microscopy, generally increases the vulnerability to artifacts (Buytaert et al., 2014). Shrinkage artifacts, due to chemical treatment 
86 (Lang, 2013) or the scanning itself (Gianoncelli et al., 2015), are very common and apart from

87 mechanical distortions (e.g. caused by bruises and cracks), cannot be fully eliminated even with

88 careful handling (Buytaert et al., 2014). Furthermore, artifacts induced by radiation or chemicals

89 might be occasionally neglected or greatly underestimated in comparative scientific reviews,

90 which might lead to erroneous interpretations.

91 Since more than one hundred years, neuroanatomists always aspired to make their findings 92 quantifiable by inventing more and more ingenious morphometric and allometric methods (see e.g. Hanström, 1926; Snell, 1891). For a meaningful interspecific comparison, quantitative data

94 referring to method-specific artifacts could serve as rewarding tool. Increasing availability of 95 neuroanatomical volumetric data, collected by the use of different methodological approaches of various arthropods (Beltz et al., 2003; Grabe et al., 2015; Hanström, 1926; Schmidt, 2016;

97 Sombke et al., 2015; Tuchina et al., 2015), raises demand for standardizing these data $a$ 98 posteriori, which constitutes the emphasis of this study. For this purpose, three different wellestablished sample preparations including two tomographic imaging techniques (confocal laserscanning microscopy and micro-computed X-ray microscopy) were performed on $P$. fallax cf. virginalis. Well identifiable and quantifiable substructures in the crayfish brain such as the deutocerebral chemosensory neuropil and the (deutocerebral) accessory neuropil served as approximation for volume change of tissues. The parthenogenetic marbled crayfish Procambarus fallax forma virginalis (Martin et al., 2010) provides for a rewarding model organism (review: uncomplicated husbandry and year-round parthenogenetic reproduction of the marbled crayfish enables replicable tests using high sample numbers (review: Vogt, 2011).

\section{Materials and Methods}

\section{Nomenclature}

111 The neuroanatomical nomenclature used in this manuscript is based on Sandeman et al. (1992)

112 and Richter et al. (2010) with some modifications adopted from Harzsch \& Hansson (2008),

113 Kenning and Harzsch (2013), and Loesel et al. (2013). The term "oesophageal connective" and 
114 the corresponding abbreviation OC (British English) are maintained here for simplicity. The

115 syncerebral brain mass excluding the lateral protocerebrum and visual neuropils of the eyestalks

116 (see Krieger et al., 2015) is termed "central brain" throughout the text according to Schmidt

117 (2016). Although, sample preparations as well as imaging techniques according to the three

118 protocols used vary in a vast of parameters that influence the resulting volume data, each of the

119 three fixatives (zinc-formaldehyde fixative, Bouin's as well as half-strength Karnovsky's

120 solution) is used as a synonym for the entire protocol throughout the text.

\section{Animals}

123 The specimens of $P$. fallax cf. virginalis used in our study were obtained from a commercial

124 aquarium shop (Aquaristik-Langer GbR, https://aquaristik-langer.de/) and were kept together in a

125 freshwater tank at the facilities of the University of Greifswald. For the experimental design,

126 berried individuals were isolated from a community tank, to ensure that all larvae originated

127 from a single individual, and hence were genetically identical. A total of 24 individuals were

128 harvested for pre-tests directly after the juveniles left the maternal pleopods. At this

129 developmental stage, the average body length (rostrum to pleon) measured about $5 \mathrm{~mm}$ and the

130 juveniles started autonomous feeding. Morphometric measurements were performed on dead and

131 undissected juveniles in order to ensure that individuals were of the same size. Morphometric

132 analysis was conducted using a Nikon eclipse 90i microscope connected to a Nikon camera DS2-

133 MBWc. For each specimen carapace length and eyestalk width were measured by using the

134 software NIS-Elements AR 3.0. Application of the Shapiro-Wilk-test using the statistical

135 software R 3.2.3 showed normal distribution for carapace length $(\mathrm{p}=0.8688)$ and eyestalk width

$136(\mathrm{p}=0.3054)$ among the samples. Subsequently, Welch's Two Sample t-test assured that there

137 was no significant difference in measured morphological characters between samples used for

138 confocal laser-scanning microscopy (cLSM) and micro-computed X-ray microscopy $(\mu \mathrm{CT})$

139 analysis (carapace length, $\mathrm{p}=0.1925$; eyestalk width, $\mathrm{p}=0.1034$ ). Furthermore, six adult

140 animals of different sizes were kindly provided by Gerhard Scholtz (Humboldt University,

141 Berlin, Germany) and kept as described above. These six specimens were used to trace

142 individual volumetric changes in three stages during sample preparation for $\mu \mathrm{CT}$. Since the

143 scanning of freshly dissected brains without adding any contrast-enhancing agent turned out to 
144 be quite challenging, this approach required the use of larger brains (approximately 170 times

145 larger than those of juveniles). Given that the number of specimens is comparably low as well as

146 we assume that the cytochemical compound of adult brains might differ from that of the juvenile

147 brain (e.g. regarding the content of lipids and proteins), the resulting shrinkage factors have to be 148 interpreted with caution.

150 General sample preparation

151 Genetically identical juveniles of Procambarus fallax $\mathrm{cf}$. virginalis from the same hatch were 152 taken out of separate tanks with plastic pipettes. They were anaesthetized by chilling them at -18 $153{ }^{\circ} \mathrm{C}$ in a beaker with little water for a few minutes. Then, the anaesthetized animals were killed by 154 transferring them into watch glasses containing $4 \%$ paraformaldehyde (PFA) and phosphate 155 buffered saline (PBS, pH 7.4; $0.1 \mathrm{M}$ ) for 30 minutes at room temperature (RT) on the shaker. 156 After that, PFA was removed by immersing the dead specimens at RT on the shaker for two 157 times (5 min each) in fresh PBS for fixation in half-strength Karnovsky's as well as Bouin's 158 solution, or in HEPES-buffered saline (HBS) for fixation in zinc-formaldehyde (ZnFA) before 159 fixation or brain dissection took place. The procedure of anaesthetization and killing of decapod 160 crustaceans is in concordance with the Animal and Welfare Scientific Panel (AHAW) of the 161 European Food Safety Authority (EFSA) from 2005.

\section{Sample preparation for $\mu \mathrm{CT}$}

164 Before $\mu \mathrm{CT}$-scanning, seven juvenile siblings were transferred into Eppendorf tubes and immersed in Bouin's solution (10 \% formaldehyde, $5 \%$ glacial acetic acid in saturated aqueous picrinic acid). Fixation took place for one week in a fridge $\left(4^{\circ} \mathrm{C}\right)$. After fixation, the animals were gradually dehydrated in ethanol at RT $(30 \%, 50 \%, 60 \%, 70 \%, 80 \%, 90 \%, 96 \%$, and $3 \times$ in $99.5 \%$ ethanol) for $30 \mathrm{~min}$ for each step. For enhancing the contrast, samples were incubated in iodine solution ( $2 \%$ iodine resublimated [Carl Roth GmbH 1 Co. KG, Karlsruhe, Germany; cat. \#X864.1] in $99.5 \%$ ethanol) for $24 \mathrm{~h}$ in the fridge. Iodine was subsequently washed out of 
171 the samples for $5 \times 3 \mathrm{~min}$ with ethanol. Wet specimens were scanned in a glue sealed pipette tip

172 filled with $99.5 \%$ ethanol (according to Sombke et al., 2015).

173

$174 \quad \boldsymbol{\mu C T}-$ Scanning

175 The scans were performed with a laboratory scaled X-ray-microscope (Xradia MicroXCT-200;

176 Carl Zeiss Microscopy $\mathrm{GmbH}$ ) entailing geometric and optical magnification. The Bouin-fixed

177 samples of $P$. fallax cf. virginalis were scanned with a $20 \times$ objective in $99.5 \%$ ethanol with a

178 voltage of $40 \mathrm{kV}$, a current of $200 \mu \mathrm{A}$, and an exposure time of 8 seconds. For all scans, binning

1792 was applied (summarizing 4 pixels for noise reduction). Projections obtained by the

180 tomography were reconstructed using the software XMReconstructor (Carl Zeiss Microscopy

$181 \mathrm{GmbH})$. To avoid consequent information loss, binning 1 (full resolution) was applied for the

182 following reconstruction resulting in image stacks of $993 \times 993$ pixels and a pixel size of about

$1831.1 \mu \mathrm{m}$. All original image stacks are openly available (see section "data processing") for

184 scientific reproducibility (Davies et al., 2017).

185 For the inference of an individual in vivo volume during $\mu \mathrm{CT}$ sample preparation and the

186 comparison of chemically-induced effects on the brain volume, brains were dissected, under tap

187 water at RT from a total of another six adult animals of different sizes, and each was

188 immediately scanned (stage 1) moistly within a sealed Eppendorf tube at $20 \mathrm{kV}$ and $3 \mathrm{~W}$ for 1

189 sec (binning 4) with 400 projections reducing the total scan time to $15 \mathrm{~min}$. Brains were

190 subsequently fixed in Bouin's solution overnight in the fridge. Bouin's solution was replaced two

191 times by tap water and the brain was immediately scanned (stage 2) again moistly using the

192 identic scanning parameters. Afterwards, these fixed brains were gradually dehydrated as

193 outlined above in addition with contrast enhancement by dissolved iodine (2\%) in ethanol before

194 being scanned a third time (stage 3 ) in $99.5 \%$ ethanol using again the same scanning parameters.

\section{Sample preparation for cLSM}

197 Fixation in half-strength Karnovsky's solution for enhancing autofluorescence of nervous 198 tissue 
199 The two pairs of antennae as well as the eyestalks were removed and the brains of a total of six

200 specimens were dissected in PBS (0.1 M; pH 7.4) using precision forceps (DUMONT®; type

201 55). The brains were fixed in half-strength Karnovsky's fixative, a mixture of $2 \%$

202 glutaraldehyde [Electron Microscopy Sciences, 1560 Industry Road, USA-Hatfield, PA 19440;

203 Cat-No. 16220] and 2 \% PFA [Carl Roth GmbH 1 Co. KG, Karlsruhe, Germany; Cat-no. 0335.2]

204 in PBS (0.1 M; pH 7.4) for a week at $4{ }^{\circ} \mathrm{C}$. Subsequently, a gradual dehydration of the samples

205 was conducted in ethanol $(50 \%, 70 \%, 80 \%, 90 \%$ for $10 \mathrm{~min}$ each, $96 \%$ for $30 \mathrm{~min}$, and in

$20699.5 \%$ ethanol for $2 \times 30 \mathrm{~min})$ at RT.

207

208 Fixation in zinc-formaldehyde and immunhistochemical labeling

209 The whole mount labeling protocol after Ott (2008) was applied to improve antibody penetration

210 into nervous tissues, as compared to traditional PFA-fixation. For this method, a total of seven

211 animals were killed by a few drops of formalin instead of $4 \%$ PFA in PBS to avoid precipitation

212 of zinc phosphate in combination with ZnFA in the following steps (compare Ott, 2008). The

213 central brain was then dissected in HBS as described before and fixed in $4 \%$ ZnFA (Electron

214 Microscopy Sciences, 1560 Industry Road, USA-Hatfield, PA 19440; Cat-No. 15675) on a

215 shaker for $20 \mathrm{~h}$ at RT. The fixed brains were subsequently washed for $3 \times 15$ min in HBS, and

216 instantly dehydrated and postfixed in DENT's fixative (20\% DMSO [Serva Electrophoresis,

217 Heidelberg, Germany; Cat-No. 20385] / 80 \% methanol) in a drop of HBS on the shaker again

218 for $2 \mathrm{~h}$, at RT. Afterwards, the brains were transferred into $99 \%$ methanol. The samples were

219 gradually rehydrated in TRIS-buffer with varying grades of methanol $(90 \%, 70 \%, 50 \%, 30 \%$

220 methanol, and finally, pure TRIS-buffer for $15 \mathrm{~min}$ each). Samples were preincubated for $2 \times 2 \mathrm{~h}$

221 in PBS-TX (0.3\% triton, $0.02 \%$ sodium azide, $1 \%$ bovine serumalbumin [BSA]) at RT,

222 followed by incubation in monoclonal mouse anti-synapsin antibody (3C11 anti SYNORF1;

223 Developmental Studies Hybridoma Bank, University of Iowa; deposited by E. Buchner,

224 University Hospital Würzburg, Germany; diluted 1:1 in glycerol) in PBS (1:1000) for 4 days at 4

$225{ }^{\circ} \mathrm{C}$. Excess primary antibody was washed in PBS-TX for 4 x $30 \mathrm{~min}$ at RT. Incubation of the Cy

226 3-conjugated secondary antibody (goat anti-mouse; Jackson Immuno Research; 1:1 in glycerol)

227 in HBS (1:500) was carried out in the fridge $\left(4^{\circ} \mathrm{C}\right)$ for 2.5 days. After washing for $2 \times 1 \mathrm{~h}$ in

228 PBS-TX, the samples were dehydrated in ethanolic solutions of different grades $(30 \%, 50 \%, 70$ 
$229 \%, 80 \%, 90 \%, 96 \%$, and $99.5 \%$ for $30 \mathrm{~min}$ each) at RT. Regarding antibody specificity, has

230 been shown that the monoclonal mouse-anti-Drosophila antibody 3C11 consistently labels

231 synaptic brain regions in representatives of all major subgroups of the malacostracan crustaceans

232 (see Beltz et al., 2003; Harzsch \& Hansson, 2008; Harzsch et al., 1997, 1999, Krieger et al.,

233 2012, 2015; Meth et al., 2017; Vilpoux et al., 2006). Hence, it can be assumed that this antibody

234 does in fact label synaptic neuropils in Malacostraca (for more details see Krieger et al., 2015).

\section{5 cLSM-scanning}

236 Scanning was conducted on a confocal laser-scanning microscope (Leica TCS SP5 II). For

237 optimal light transmission, tissues were cleared in $98 \%$ methyl salicylate (Merck, Darmstadt,

238 Germany; Cat-no. W274518). After dehydration in ethanol, brains that were previously fixed in

239 ZnFA $(n=7)$ as well as in half-strength Karnovsky's solution $(n=6)$ were transferred into custom-

240 made scan chambers filled with pure methyl salicylate before confocal laser-scanning. Scanning

241 was performed with an inverted Leica TCS SP5II (Leica, Wetzlar, Germany) using a DPSS-laser

242 with an excitation wavelength of $561 \mathrm{~nm}$ and a speed of $400 \mathrm{~Hz}$. For detection of fluorescence

243 (emitted by glutaraldehyde-enhanced autofluorescence as well as by Cy3-conjugates of the

244 secondary antibody), a $10 \mathrm{x}$ objective with a numerical aperture of 0.4 was used resulting in

245 stacked images of $1024 \times 1024$ pixels with a pixel size of about $0.8 \mu \mathrm{m}$. The confocal

246 microscope operated with a pinhole size of $53 \mu \mathrm{m}$ in diameter and in steps of $1.33 \mu \mathrm{m}$ (system-

247 optimized to 1 airy unit and refractive correction for aqueous immersion media).

\section{Data processing}

250 Volume reconstruction and visualization was carried out using Amira 5.6.0. (FEI Visualization

251 Science Group, Burlington, USA). The central brain, the deutocerebral chemosensory lobes

252 (DCLs) as well as the accessory lobes (AcNs) were segmented manually for volumetric analysis.

253 Three-dimensional surfaces corresponding to the segmentation were generated using

254 unconstrained smoothing (Amira: SurfaceGen). Voxel data of the reconstructed neuropils were

255 extracted by using Amira`s material statistics tool. The outline of scans of dissected brains could

256 be instantly visualized without further virtual segmentation by using the Amira Isosurface- 
257 module. Morphological deformations based on anisometric shrinkages could be detected this 258 way.

259 Raw data of brain section series (based on $\mu \mathrm{CT}$ as well as cLSM) is available from 260 https://www.morphdbase.de (Grobe \& Vogt, 2009) under the "media" tab under "Krieger". A 261 combination of the short title "Nischik and Krieger (2017) Marmorkrebs", an identifier 262 according to the specimen, and an abbreviation for the method applied (e.g. Nischik and Krieger 263 (2017) Marmorkrebs01_ $\mu \mathrm{CT}$ ) is given for each of the 20 image stacks in addition to 18 image 264 stacks of brains of another six adult specimens which were scanned 1) freshly dissected prior to 265 fixation; 2) fixed with Bouin's solution overnight but without any dehydration as well as any 266 contrast agent; and 3) after fixation, dehydration in ethanol, and contrast enhancement using $2 \%$ iodine. Please note that due to technical requirements of MorphDBase ver. 3.3, all $\mu \mathrm{CT}$-datasets had to be reduced in color depth from 16 bit to 8 bit prior to uploading. In contrast to the datasets from $\mu \mathrm{CT}$-scanning, all cLSM-based datasets feature anisotropic voxels. The original voxel-size is lost due to a conversion of the file format prior to uploading. For displaying these image stacks in the correct spatial relationship, the voxel-size has to be resized for each image stack according to the voxel dimensions given in table 1 (including the correction factor to minimize refractive mismatch from Bucher et al. (2000) of 1.581 in the z-axis).

274 Furthermore, table 2 summarizes the volumes of the central brain, of the DCLs, and AcNs of

275 both brain hemispheres according to the three methods applied as well as the z-corrected 276 volumes due to a putative refractive mismatch in cLSM-scans. In table 3, the volumes of the 277 central brain of six adult specimens are summarized which were analyzed for evaluation of tissue 278 shrinkage throughout the sample preparation (stages 1 to 3 ) prior to $\mu \mathrm{CT}$-scanning of fixed and 279 contrast-enhanced samples.

\section{Statistics}

282 The acquired volume data (Fig. 1) were exported into Microsoft@ Excel for descriptive statistics. 283 Statistical analyses were performed with the "stats"-package and illustrated with the "graphics"284 package of R 3.2.3. A one-way analysis of variance (ANOVA) was carried out for calculation of statistical significant differences between volumetric data and the methods used (Fig. 2). The 
286 effects of treatment on the volume of the subunits DCLs and AcNs, as well as on the total

287 volume of the central brain were calculated for each structure by Tukey's post-hoc test. A paired

288 two sample Student's t-test was applied for volumes of left and right lobe of AcN and DCL

289 respectively, to test reproducibility of the manual volume reconstruction, which was conducted

290 by the same investigator for each specimen. A Wilcoxon signed rank test was applied to test the

291 effect of chemically induced difference in the brain volume throughout the sample preparation

292 for $\mu$ CT-scanning.

293

294 Results

295

$\mu \mathrm{CT}$

296 Tomograms were generated with $\mu \mathrm{CT}$ to morphometrically analyze the brain of $P$. fallax $\mathrm{cf}$.

297 virginalis. Volume rendering allowed virtually sectioning of the animal in different planes for

298 neuroanatomical analysis as well as visualizing the brain in its natural position within the

299 cephalon (Figs. 3A to D). The image contrast as a function of the tissue density was high enough

300 to allow identification of single neuropils (compare Figs. 4A and B). Thus, the central brain

301 including the DCLs and the AcNs could be reconstructed (Figs. 3C and D). The central brain is

302 vertically curved and held in its upright position by the protocerebral tract originating in the

303 lateral protocerebrum (latPC; Figs. 3C and D) within the eyestalks as well as by the nerves of the

304 antennae 1 and $2\left(\mathrm{~A}_{\mathrm{I}}\right.$ and $\mathrm{A}_{\mathrm{II}}$; Figs. 3A and $\left.\mathrm{C}\right)$. Here, an approximate in situ coherent

305 reconstruction of the neuropils in their spatial context is assumed, since only a few steps of

306 sample preparation were required for scanning an animal as a whole.

307

308 While $\mu \mathrm{CT}$-scanning of contrasted tissues delivered a high image contrast, the analysis of $\mu \mathrm{CT}$ -

309 scans of unfixed as well as fixed brains (without any contrast agent) of another six adult

310 specimens, which were used for inferring individual in vivo volumes during $\mu \mathrm{CT}$ sample

311 preparation, turned out to be fairly challenging. In freshly dissected as well as in Bouin-fixed but

312 uncontrasted brains, the image contrast was barely high enough to identify the limits of the tissue

313 surfaces but did not suffice to identify internal substructures such as neuropils or cell clusters.

314 Therefore, the use of larger brains of adult specimens (approximately 170 times larger than those 
315 of juveniles) was essential. The central brain volume resulted in a significant average shrinkage

316 of $24 \%$ (ranging from 7.9 to $44.8 \%$ ) after fixation in Bouin's solution (Wilcoxon signed rank

317 test: $\mathrm{p}=0.0313 ; \mathrm{n}=6$ ) and no further significant shrinkage (Wilcoxon signed rank test: $\mathrm{p}=$

$3180.6875 ; \mathrm{n}=6$ ) after dehydration and contrast-enhancement using $2 \%$ iodine in ethanol (Fig. 5

319 and table 3).

320

321

\section{2 cLSM}

323 Autofluorescence in half-strength Karnovsky's solution

324 Tissues fixed with half-strength Karnovsky's solution resulted in cLSM scans characterized by a

325 high resolution and remarkable signal to noise ratio. Furthermore, intricate histological details

326 such as individual olfactory glomeruli in the DCL and even microglomeruli within the AcN were

327 resolved with high accuracy (compare Figs. 4A and C).

328

329

Immunhistochemistry, ZnFA-Fixation

330 In comparison to the previously described method, volume divergences may only be the result of

331 the fixation of the specimen - in this case using the ZnFA-fixation protocol after Ott (2008) and,

332 of course, of the individual bias, due to manual segmentation for three-dimensional

333 reconstruction in Amira. In fact, the reconstructed volumes differ only slightly, and thus, no

334 statistically significant difference between the applied fixations (ZnFA and half-strength

335 Karnovsky's solution) could be detected for each of the brain substructures analyzed (Fig. 2).

336 However, a slightly higher average volume indicates, that the whole brain is somewhat better

337 preserved by using the fixation with $\mathrm{ZnFA}$ and dehydrogenation in methanol and DMSO. Since

338 an immunohistochemical labeling was used here, the resulting tissue contrast is different to that

339 of autofluorescence in half-strength Karnovsky's solution (compare Figs. 4C and D). In this case,

340 primarily areas in which the synaptic membrane protein synapsin was present were stained (Fig.

341 4D). While the intention was to facilitate the identification of neuropil regions, it actually

342 increased image noise.

343

$\mu \mathrm{CT}$ versus CLSM 
345 All three methods very likely differ to a certain degree from in vivo congruent nervous tissue

346 volume. Since all samples at least temporarily were exposed to hyperosmolar media resulting in

347 dehydration, it has to be assumed that artifacts due to shrinkage most likely occurred. An

348 expansion of the tissue seems unlikely, since also in the wet-scan $\mu \mathrm{CT}$ approach, dehydration

349 takes place (e.g. fixation in Bouin's solution, dehydration in ethanol). However, neither the

350 general imaging technique ( $\mu$ CT $v s$. cLSM: Welch's Two Sample t-test: $\mathrm{p}=0.2136 ; \mathrm{n}=20)$, nor

351 the choice of fixative between both cLSM approaches did influence the tissue volumes

352 significantly (Welch's Two Sample t-test: $\mathrm{p}=0.4541 ; \mathrm{n}=13$ ). Assuming a symmetrical

353 development of both brain hemispheres, the investigator's individual bias in manual

354 segmentation for three-dimensional reconstruction was tested by comparing volumes of both

355 hemispheres. While the volume of the accessory lobes reliably exceeded the volume of the

356 deutocerebral chemosensory lobes (single-factor ANOVA: $\mathrm{p}<0.001 ; \mathrm{n}=20$ ), no difference in

357 the volume of the left and right hemispheres of paired lobes could be found in any given

358 treatment (paired Student's t-test: DCL: $\mathrm{p}=0.2691$; AcN: $\mathrm{p}=0.1107 ; \mathrm{n}=20$ ).

359

360 The highest DCLs-volumes (total volume of both hemispheres) were reconstructed in specimens

361 which were fixed in Bouin's solution and imaged by the use of $\mu$ CT (mean DCLs volume [ $\mathrm{mm}^{3}$ ]:

$3620.0029 \pm 0.0003 ; \mathrm{n}=7$ ). The DCLs volumes in specimens fixed in ZnFA (mean DCLs volume

$\left.363\left[\mathrm{~mm}^{3}\right]: 0.0027 \pm 0.0006 ; \mathrm{n}=7\right)$ were insignificantly higher compared to specimens fixed in half-

364 strength Karnovsky's solution (mean DCLs volume $\left[\mathrm{mm}^{3}\right]: 0.0025 \pm 0.0003 ; \mathrm{n}=6$ ). The

365 measured volume of nervous tissue was most congruent to assumed in vivo volume when

366 specimens were fixed in Bouin and scanned in ethanol with $\mu \mathrm{CT}$ (Figs 1, 2, and 5). This is

367 followed by cLSM visualization of whole-mounts fixed in ZnFA and at last of tissues fixed in

368 half-strength Karnovsky's solution (compare Figs. 1A, B, and C). Although $\mu$ CT derived

369 volumes are significantly smaller than those of freshly dissected brains (average of $24 \%$,

370 ranging from 7.9 to $44.8 \%$ ), cLSM tomograms of tissues fixed in half-strength Karnovsky's

371 solution reveal a further relative shrinkage of $12.5 \%$; and of $5 \%$ when using ZnFA-fixation.

372

373 In P. fallax cf. virginalis, light-microscopic imaging techniques on the brain require the removal

374 of the cuticle or dissection of the nervous tissue, thus an analysis of the brain within the animal is

375 only feasible by using x-ray -or magnetic resonance imaging techniques (Brinkley et al., 2005; 
376 Herberholz et al., 2004; Köhnk et al., 2017, and reviewed in Ziegler et al., 2011). Three-

377 dimensional surfaces of half-strength Karnovsky's solution-fixed brains, based on isosurfaces

378 using a grayscale-threshold (Amira: Isosurface), appeared more porous and wrinkled (compare

379 Figs. 6A to C), while the ZnFA-fixed brains had a smoother appearance (compare Figs. 6D to F).

380 Along the neuraxis, brains appear more furrowed after fixation with half-strength Karnovsky's

381 solution compared to those fixed with ZnFA (Figure 6). In addition, the bilaterally symmetric

382 antenna-2-nerve $\left(\mathrm{A}_{\mathrm{II}} \mathrm{Nv}\right.$; Figs. $6 \mathrm{D}$ and $\left.\mathrm{F}\right)$ was better preserved in its fibrous organization in $\mathrm{ZnFA}$

383 preparations compared to those fixed with half-strength Karnovsky's solution (Figs. 6A and C).

384 For comparison of image quality, a schematic overview of the central brain (Fig. 4A) as well as

385 virtual frontal sections recorded on a similar anatomical plane (approximately as shown in Fig.

386 3B) are shown in Figure 4B to D. In images generated by cLSM within the DCL, individual

387 olfactory glomeruli are visible (Figs. $4 \mathrm{C}$ and D). The images produced by $\mu \mathrm{CT}$ have a lower

388 resolution and a lower signal-to-noise ratio. Here, the identification of individual olfactory

389 glomeruli at least at the chosen magnification is not possible (Figure 4B). In fact, the highest

390 contrast was obtained by confocal imaging of half-strength Karnovsky's solution-fixed tissue

391 (Fig. 4C). By the use of autofluorescent enhancement of half-strength Karnovsky's solution-

392 fixation, the sample preparation is much less time consuming but more unspecific than applying

393 the two-step protocol of immunhistochemical labeling. The high resolution in both methods

394 reveals details like individual olfactory glomeruli of the DCLs as well as even microglomeruli

395 within the AcNs (Figs. 4A, C, and D).

396

397 Discussion

398 Confocal laser-scanning microscopy turned out to be the most suitable technique for

399 identification of neuropils and neuronal somata (Figs. 4A, C, and D). Nevertheless, for the use of

400 brain morphometry at a coarse level, the image contrast is sufficient to distinguish the neuropils

401 from the surrounding tissue in all applied techniques. In contrast to the preparation for $\mu \mathrm{CT}$, the

402 central brain has to be dissected for cLSM whole mounts, which comes with some

403 disadvantages. The process of sample preparation alters the brain's characteristic shape, which

404 in-situ is displaying a curvature along the neuraxis. Due to dissection, the originally upstanding

405 central brain collapses so that spatial relationships of brain regions become artificial. In addition,

406 the use of methyl salicylate for clearing in advance of cLSM-scanning has been reported to cause 
407 unpredictable shrinkage of nervous tissues ranging from 3.5 to $27 \%$ of the volume (Bucher et 408 al., 2000). Furthermore, a refractive mismatch along the z-axis must be considered for the use of 409 methyl salicylate as mounting medium for cLSM whichleads to enormous aberrations of volume 410 (Bucher et al., 2000). Using the $\mathrm{z}$-axial correction factor to eliminate refractive mismatch for the 411 use of methyl salicylate provided by Bucher et al. (2000) of 1.581 (for a 10x dry objective with a 412 numerical aperture of 0.40 ) resulted in spatial congruence of the brain dimensions that almost 413 equals those based on $\mu \mathrm{CT}$-scans. The resulting volumes of brains fixed in ZnFA as well as in 414 half-strength Karnovsky's solution were still insignificantly smaller (ZnFA vs. Bouin: $5 \%$; $=$ 415 0.826; half-strength Karnovsky’s solution vs. Bouin: $12.5 \%$; $=0.362$; one-way ANOVA) than 416 those obtained from $\mu \mathrm{CT}$-scans. The refractive mismatch is often altered bythe anisometric 417 distribution of clearing agent, different refractive indices of the tissues analyzed and thus, its 418 progression along the z-axis is not linear (Hell et al., 1993; Besseling, Jose \& Blaaderen, 2015).

419 The anisometry of cLSM-stacks as a result of optical limitations and the associated necessity of a 420 z-axial correction factor prior to analysis hence adds another source of inaccuracy compared to $421 \mu \mathrm{CT}$-datasets. Although, brain volumes based on cLSM-stacks that were axially rescaled are 422 insignificantly smaller, the sample preparation seems to have a higher influence on tissue 423 shrinkage than the sample preparation for $\mu \mathrm{CT}$-scanning. Also, the accuracy of volumetric 424 analysis is decreased when using the fixation of ZnFA in addition with immunohistochemical 425 labeling against synapsins compared to the sample preparations using Bouin and half-strength 426 Karnovsky's solution, resulting in higher variances. One explanation could be that since the 427 latter two approaches (using Bouin as well as half-strength Karnofsky's solution) are based on 428 the detection of differences in tissue densities, the sample preparation using ZnFA is basically 429 dependent on the cross-linking of the antibody against SYNORF1, and thus the distribution of 430 the target epitopes.

431

432 While volumetry can be helpful to analyze differences in the size relation of brain structures 433 within an organism, as well as for interspecific comparison, referring brain size as a function of 434 cognitive capacity, is highly debated (Chittka \& Niven, 2009; Healy \& Rowe, 2013). However, 435 for example in honeybees (Durst et al., 1994; Groh et al., 2006) or in leaf-cutting ants (Groh et 436 al., 2014), morphometric analysis showed an age and experience dependent difference in 437 neuropil volume of the mushroom body. Especially for the volumetry of these tiny brain 
438 subcompartiments, measurement errors can have a huge impact and should therefore be

439 minimized. It is therefore important to consider the osmolality of immersive chemicals (fixatives

440 and buffers) in respect to the target tissue. Increased tissue shrinkage was reported with

441 increasing hypertonia (Rasmussen, 1974), hence chemical fixatives with similar osmolality as

442 the original osmotic environment (e.g. $<280 \mathrm{mOsm} / \mathrm{kg} \mathrm{H}_{2} \mathrm{O}$ for freshwater species) are

443 recommended (Bullock, 1984; Coetzee \& van der Merwe, 1985). An area shrinkage of $11-20 \%$

444 was reported for rabbit corneal endothelial cells fixed with Karnovsky fixative ( $850 \mathrm{mOsM} / \mathrm{kg}$;

445 Doughty et al., 1997). However, in the current study merely a half-strength Karnovsky fixative

446 (640 mOsM/kg; Platt et al., 1997) was applied. Ott (2008) described a new fixation protocol for

447 immunhistochemical staining, which uses ZnFA instead of PFA resulting in lower osmolality

$448(325 \mathrm{mOsm} / \mathrm{kg})$. This has been shown to improve antibody penetration and preservation of

449 spatial brain morphology. Ott (2008) demonstrated effects of different fixation protocols on

450 morphological preservation on the brain of the desert locust Schistocerca gregaria. Ott showed

451 that fixation using PFA lead to increased wrinkling in contrast to ZnFA-fixation. Likewise, the

452 nature of dehydration and the duration of fixation were found to be decisive factors. This

453 corresponds to findings from Ott (2008), as preparations with a shorter fixing time in ZnFA

454 showed a lower wrinkling. Here, the cLSM-tomograms resulted in smoother surfaces of brains

455 analyzed.

456 Apart from indirect volumetric measurements evaluated here, a possible approach to obtain 457 approximate in vivo volumes for invertebrate brains, would be the use of a micro-volumeter 458 according to Douglass and Wcislo (2010), as an example for direct volumetry. By the use of 459 Archimedes' principle, the dissected brain is put in a liquid-filled tube and the occurring volume 460 displacement of the liquid can be measured with a micro-pipette stepwise until the previous 461 meniscus is reached. In this way, the total removed volume equals the actual brain volume.

462 However, based on initial trials, instrumental errors still outweigh a precise measurement of very 463 small volumes $(<1 \mathrm{ml})$. This technique needs more precise adjustment for readout of the 464 meniscus. A successful application of direct volumetry using Archimede's principle or high 465 resolution magnetic resonance imaging of living animals will offer a conclusive reference for in 466 vivo brain volumes. Although the sample size is not markedly high $(\mathrm{n}=$ ranging from 6 to 7 per 467 treatment), we consider that specimens prepared for $\mu \mathrm{CT}$ feature the closest in vivo coherence 468 (24\% average shrinkage; ranging from 7.9 to $44.8 \%$ ). We could show that shrinkage due to 
469 each single step throughout the sample preparation was primarily influenced by the fixation in

470 Bouin, whereas the subsequent steps of this preparation interestingly did not contribute

471 substantially to tissue shrinkage. However, dehydration in ethanol in addition with contrast-

472 enhancement by iodine (Buytaert et al., 2014) as well as the scanning procedure itself

473 (Gianoncelli et al., 2015) indeed most likely lead to a deviation from the in vivo volume.

474 The deutocerebral chemosensory and accessory lobes are convenient landmarks for a volumetric 475 evaluation of experimental effects, due to their conspicuous structure with an almost spherical

476 shape, they can be easily identified. Especially for the conspicuous deutocerebral chemosensory

477 lobes, volumetric data are available for a considerable number of crustacean species (see Beltz et

478 al., 2003; Krieger et al., 2015; Tuchina et al., 2015; and review in Schmidt, 2016). In particular,

479 the relative volumes of these homologous brain regions vary greatly among species. For

480 comparison, table 4 displays the volume information for the deutocerebral chemosensory lobes

481 of selected crustacean species accompanied by the data obtained for $P$. fallax cf. virginalis.

482 However, it should be noted that all individuals of $P$. fallax cf. virginalis analyzed for the

483 comparison of imaging techniques were juvenile siblings with a body length of about $5 \mathrm{~mm}$.

484 Adults of this species can reach a body length of $120 \mathrm{~mm}$, and thus feature markedly larger brain

485 sizes (ranging up to 300 times higher volumes than those of the juveniles analyzed here).

486 Furthermore, it can be expected that methods including chemicals do not influence volumes of

487 different brain substructures alike (such as somata or fibers). Since the main volume of the brain

488 is dominated by neuropils as well as the fact that all three methodological approaches did not

489 meet the requirements of a differentiated volumetric analysis, an inhomogeneous tissue

490 shrinkage was neglected for simplicity.

491 For interspecific comparisons and the corresponding phylogenetic or neuroanatomical value of

492 volumetric data, several factors have to be standardized, such as the experimental procedure

493 including fixatives and technique of volumetry (e.g. histological sections with volumetric

494 extrapolations based on the section thickness, or 3D-reconstruction of tomographic data).

495 Shrinkage factors, based on the morphometric method and fixatives used, can serve as a tool to

496 approximate already referred volumetric data to a common denominator for a more reasonable

497 interspecific comparison. Because of its parthenogenetic nature, $P$. fallax cf. virginalis is well

498 suited generating such a reference system at least for aquatic arthropods featuring a comparable 
499

500

501

502

503

504

505

506

507

508

509

510

511

512

513

514

515

516

517

518

519

520

521

522

523

524

525

526

527

osmolality. Although the juvenile specimens analyzed were genetically identical and of the same age (clutch), individual brain sizes might vary due to phenotypic plasticity as has been shown e.g. for the marmoration pattern in siblings of the Marmorkrebs (review: Vogt, 2011), but also for brain sizes in clones of Daphnia magna (Macagno et al., 1973), and also in vertebrates (review: Mitchell, 2007). Consequently, comparative brain allometry in juvenile isogenetic siblings appears to be the most favorable approximation to neglect inter-individual variations.

\section{Conclusions}

Although today, neuroanatomical volumetric data are available for a variety of crustacean species, interspecific comparisons often suffer from methodological differences in volumetry. Variations in tissue volume as artefacts of experimental sample preparation, such as fixation procedures, might be incorrectly assigned to biological phenomena. While comparative brain morphometry and especially volumetry as a measure for cognitive capabilities is controversially discussed (Chittka \& Niven, 2009; Healy \& Rowe, 2013), it is, however, a useful tool for other fields of interest, such as the neural development (Helluy et al., 1995), neurophylogeny as well as specific evolutionary adaptations of the nervous system (Beltz et al., 2003; Krieger et al., 2015; reviewed in Schmidt, 2016). Therefore, a standardization of method-based deviations is highly recommended. Here, we aimed at a consistent methodological approach to evaluate standard imaging techniques as well as to obtain conversion factors to deduce approximate in vivo volumes based on the method of analysis. Well-founded conversion factors will allow for $a$ posteriori standardization of determined nervous tissue volumes in malacostracans, and therefore help to eliminate the aforementioned sources of error. Due to its parthenogenetic reproduction, $P$. fallax cf. virginalis produces genetically identical offspring making it an ideal model organism especially for methodological studies. Further comparative studies covering all standard techniques in the same manner, will offer a conclusive reference system and comparability, irrespective of fixation protocol chosen which is indeed dependent of the imaging technique and the specific scientific question. 


\section{Acknowledgements}

529 We cordially thank Gerhard Scholtz (Humboldt-University of Berlin) for the kind provision of

530 animals and Caroline Viertel (University of Greifswald) for the animal husbandry in the

531 laboratory. We like to express our gratitude to Steffen Harzsch and Marie K. Hörnig (University

532 of Greifswald) for reading and improving the manuscript. We would like to thank both

533 anonymous reviewers for their input, as these recommendations led us to markedly improve the

534 manuscript.

\section{References}

537

538

539

540

541

542

543

544

545

546

547

548

549

550

Akkari N., Enghoff H., Metscher BD. 2015. A New Dimension in Documenting New Species: High-Detail Imaging for Myriapod Taxonomy and First 3D Cybertype of a New Millipede Species (Diplopoda, Julida, Julidae). PLOS ONE 10:e0135243. DOI: 10.1371/journal.pone.0135243.

Beltz BS., Kordas K., Lee MM., Long JB., Benton JL., Sandeman DC. 2003. Ecological, evolutionary, and functional correlates of sensilla number and glomerular density in the olfactory system of decapod crustaceans. The Journal of Comparative Neurology 455:260-269. DOI: 10.1002/cne.10474.

Besseling TH., Jose J., Blaaderen AV. 2015. Methods to calibrate and scale axial distances in confocal microscopy as a function of refractive index. Journal of Microscopy 257:142150. DOI: $10.1111 /$ jmi.12194.

Brinkley CK., Kolodny NH., Kohler SJ., Sandeman DC., Beltz BS. 2005. Magnetic resonance imaging at $9.4 \mathrm{~T}$ as a tool for studying neural anatomy in non-vertebrates. Journal of Neuroscience Methods 146:124-132. DOI: 10.1016/j.jneumeth.2005.02.003. 
551 Bucher D., Scholz M., Stetter M., Obermayer K., Pflüger H-J. 2000. Correction methods for

552 three-dimensional reconstructions from confocal images: I. tissue shrinking and axial

553

554 scaling. Journal of Neuroscience Methods 100:135-143. DOI: 10.1016/S0165-

555 0270(00)00245-4.

Bullock GR. 1984. The current status of fixation for electron microscopy: A review. Journal of Microscopy 133:1-15. DOI: 10.1111/j.1365-2818.1984.tb00458.x.

557

558

559

560

561

562

563

564

565

566

567

568

569

570

571

572

573

Buytaert J., Goyens J., De Greef D., Aerts P., Dirckx J. 2014. Volume shrinkage of bone, brain and muscle tissue in sample preparation for micro-CT and light sheet fluorescence microscopy (LSFM). Microscopy and Microanalysis 20:1208-1217. DOI: $10.1017 / \mathrm{S} 1431927614001329$.

Chittka L., Niven J. 2009. Are Bigger Brains Better? Current Biology 19:R995-R1008. DOI: 10.1016/j.cub.2009.08.023.

Coetzee J., van der Merwe CF. 1985. Effect of glutaraldehyde on the osmolarity of the buffer vehicle. Journal of Microscopy 138:99-105. DOI: 10.1111/j.1365-2818.1985.tb02602.x.

Davies TG., Rahman IA., Lautenschlager S., Cunningham JA., Asher RJ., Barrett PM., Bates KT., Bengtson S., Benson RBJ., Boyer DM., Braga J., Bright JA., Claessens LPAM., Cox PG., Dong X-P., Evans AR., Falkingham PL., Friedman M., Garwood RJ., Goswami A., Hutchinson JR., Jeffery NS., Johanson Z., Lebrun R., Martínez-Pérez C., MarugánLobón J., O’Higgins PM., Metscher B., Orliac M., Rowe TB., Rücklin M., SánchezVillagra MR., Shubin NH., Smith SY., Starck JM., Stringer C., Summers AP., Sutton MD., Walsh SA., Weisbecker V., Witmer LM., Wroe S., Yin Z., Rayfield EJ., Donoghue PCJ. 2017. Open data and digital morphology. Proc. R. Soc. B 284:20170194. DOI: 10.1098/rspb.2017.0194. 
574 Dinley J., Hawkins L., Paterson G., Ball A d., Sinclair I., Sinnett-Jones P., Lanham S. 2010.

575 Micro-computed X-ray tomography: a new non-destructive method of assessing

576 sectional, fly-through and 3D imaging of a soft-bodied marine worm. Journal of Microscopy 238:123-133. DOI: 10.1111/j.1365-2818.2009.03335.x.

Doughty MJ., Bergmanson JPG., Blocker Y. 1997. Shrinkage and distortion of the rabbit corneal endothelial cell mosaic caused by a high osmolality glutaraldehyde-formaldehyde fixative compared to glutaraldehyde. Tissue and Cell 29:533-547. DOI: 10.1016/S0040-

Douglass J., Wcislo W. 2010. An inexpensive and portable microvolumeter for rapid evaluation of biological samples. BioTechniques 49:566-572. DOI: 10.2144/000113464.

Durst C., Eichmüller S., Menzel R. 1994. Development and experience lead to increased volume 585 of subcompartments of the honeybee mushroom body. Behavioral and Neural Biology

Faulwetter S., Vasileiadou A., Kouratoras M., Dailianis T., Arvanitidis C. 2013. Microcomputed tomography: Introducing new dimensions to taxonomy. ZooKeys 263:1-45. DOI: $10.3897 /$ zookeys.263.4261.

590 Gianoncelli A., Vaccari L., Kourousias G., Cassese D., Bedolla DE., Kenig S., Storici P., Lazzarino M., Kiskinova M. 2015. Soft X-Ray Microscopy Radiation Damage On Fixed Cells Investigated With Synchrotron Radiation FTIR Microscopy. Scientific Reports 5:10250. DOI: $10.1038 /$ srep 10250 .

594 Gignac PM., Kley NJ., Clarke JA., Colbert MW., Morhardt AC., Cerio D., Cost IN., Cox PG., Daza JD., Early CM., Echols MS., Henkelman RM., Herdina AN., Holliday CM., Li Z., Mahlow K., Merchant S., Müller J., Orsbon CP., Paluh DJ., Thies ML., Tsai HP., Witmer 
LM. 2016. Diffusible iodine-based contrast-enhanced computed tomography (diceCT): an emerging tool for rapid, high-resolution, 3-D imaging of metazoan soft tissues. Journal of Anatomy 228:889-909. DOI: 10.1111/joa.12449.

600

601

602

603

604 605

606

607

608

609

610

611

612

613

614

615

616

617

Grabe V., Strutz A., Baschwitz A., Hansson BS., Sachse S. 2015. Digital in vivo 3D atlas of the antennal lobe of Drosophila melanogaster. Journal of Comparative Neurology 523:530544. DOI: 10.1002/cne.23697.

Grobe P., Vogt L. 2009. Morph.D.Base 2.0: A public data base for morphological data, metadata, and phylogenetic matrices.

Groh C., Ahrens D., Rössler W. 2006. Environment- and Age-Dependent Plasticity of Synaptic Complexes in the Mushroom Bodies of Honeybee Queens. Brain, Behavior and Evolution 68:1-14. DOI: 10.1159/000092309.

Groh C., Kelber C., Grübel K., Rössler W. 2014. Density of mushroom body synaptic complexes limits intraspecies brain miniaturization in highly polymorphic leaf-cutting ant workers. Proceedings of the Royal Society of London B: Biological Sciences 281:20140432. DOI: 10.1098/rspb.2014.0432.

Handschuh S., Baeumler N., Schwaha T., Ruthensteiner B. 2013. A correlative approach for combining microCT, light and transmission electron microscopy in a single 3D scenario. Frontiers in Zoology 10:44. DOI: 10.1186/1742-9994-10-44.

Hanström B. 1926. Untersuchungen über die relative Grösse der Gehirnzentren verschiedener Arthropoden unter Berücksichtigung der Lebensweise. Zeitschrift fur MikroskopischAnatomische Forschung 7:135-190. 
618 Harzsch S., Anger K., Dawirs RR. 1997. Immunocytochemical detection of acetylated alpha-

619 tubulin and Drosophila synapsin in the embryonic crustacean nervous system. The 620 International Journal of Developmental Biology 41:477-484.

621 Harzsch S., Hansson BS. 2008. Brain architecture in the terrestrial hermit crab Coenobita 622 clypeatus (Anomura, Coenobitidae), a crustacean with a good aerial sense of smell. BMC 623 Neuroscience 9:58. DOI: 10.1186/1471-2202-9-58.

624 Harzsch S., Krieger J., Faulkes Z. 2015. "Crustacea": Decapoda - Astacida. In: Wanninger A ed. 625 Evolutionary Developmental Biology of Invertebrates 4. Springer Vienna, 101-151. DOI: 10.1007/978-3-7091-1853-5_4.

Harzsch S., Miller J., Benton JL., Beltz BS. 1999. From embryo to adult: persistent neurogenesis and apoptotic cell death shape the lobster deutocerebrum. Journal of Neuroscience $19: 3472-3485$.

Healy SD., Rowe C. 2013. Costs and benefits of evolving a larger brain: doubts over the evidence that large brains lead to better cognition. Animal Behaviour 86:e1-e3. DOI: 10.1016/j.anbehav.2013.05.017.

633
Hell S., Reiner G., Cremer C., Stelzer EHK. 1993. Aberrations in confocal fluorescence microscopy induced by mismatches in refractive index. Journal of Microscopy 169:391405. DOI: 10.1111/j.1365-2818.1993.tb03315.x.

Helluy SM., Ruchhoeft ML., Beltz BS. 1995. Development of the olfactory and accessory lobes in the american lobster: An allometric analysis and its implications for the deutocerebral structure of decapods. The Journal of Comparative Neurology 357:433-445. DOI: 10.1002/cne.903570308. 
640 Henne S., Friedrich F., Hammel JU., Sombke A., Schmidt-Rhaesa A. 2016. Reconstructing the

641

642

643

644

645

646

647

648

649

650

651

652

653

654

655

656

657

658

659

660

661

anterior part of the nervous system of Gordius aquaticus (Nematomorpha, cycloneuralia) by a multimethodological approach. Journal of Morphology 278:106-118. DOI: 10.1002/jmor.20623.

Herberholz J., Mims CJ., Zhang X., Hu X., Edwards DH. 2004. Anatomy of a live invertebrate revealed by manganese-enhanced Magnetic Resonance Imaging. Journal of Experimental Biology 207:4543-4550. DOI: 10.1242/jeb.01328.

Holst S., Michalik P., Noske M., Krieger J., Sötje I. 2016. Potential of X-ray micro-computed tomography for soft-bodied and gelatinous cnidarians with special emphasis on scyphozoan and cubozoan statoliths. Journal of Plankton Research 38:1225-1242. DOI: 10.1093/plankt/fbw054.

Kenning M., Harzsch S. 2013. Brain anatomy of the marine isopod Saduria entomon Linnaeus, 1758 (Valvifera, Isopoda) with special emphasis on the olfactory pathway. Frontiers in Neuroanatomy 7:1-14. DOI: 10.3389/fnana.2013.00032.

Köhnk S., Baudewig J., Brandis D., Boretius S. 2017. What's in this crab? MRI providing highresolution three-dimensional insights into recent finds and historical collections of Brachyura. Zoology 121:1-9. DOI: 10.1016/j.zool.2016.11.004.

Krieger J., Braun P., Rivera NT., Schubart CD., Müller CHG., Harzsch S. 2015. Comparative analyses of olfactory systems in terrestrial crabs (Brachyura): evidence for aerial olfaction? PeerJ 3:e1433. DOI: 10.7717/peerj.1433.

Krieger J., Sombke A., Seefluth F., Kenning M., Hansson BS., Harzsch S. 2012. Comparative brain architecture of the European shore crab Carcinus maenas (Brachyura) and the 
common hermit crab Pagurus bernhardus (Anomura) with notes on other marine hermit crabs. Cell and Tissue Research 348:47-69. DOI: 10.1007/s00441-012-1353-4.

664 Lang G. 2013. Fixierung. In: Histotechnik. Springer Vienna, 47-77. DOI: 10.1007/978-3-7091665 1190-1_5.

666 Loesel R., Wolf H., Kenning M., Harzsch S., Sombke A. 2013. Architectural principles and 667 evolution of the arthropod central nervous system. In: Minelli A, Boxshall G, Fusco G 668 eds. Arthropod Biology and Evolution. Berlin Heidelberg: Springer, 299-342.

Macagno ER., Lopresti V., Levinthal C. 1973. Structure and Development of Neuronal Connections in Isogenic Organisms: Variations and Similarities in the Optic System of Daphnia magna. Proceedings of the National Academy of Sciences of the United States of America 70:57-61. DOI: 10.1073/pnas.70.1.57.

Martin P., Dorn NJ., Kawai T., van der Heiden C., Scholtz G. 2010. The enigmatic Marmorkrebs (marbled crayfish) is the parthenogenetic form of Procambarus fallax (Hagen, 1870). Contributions to Zoology 79.

Meth R., Wittfoth C., Harzsch S. 2017. Brain architecture of the Pacific White Shrimp Penaeus vannamei Boone, 1931 (Malacostraca, Dendrobranchiata): correspondence of brain structure and sensory input? Cell and Tissue Research:1-17. DOI: 10.1007/s00441-0172607-y.

Metscher BD. 2009. MicroCT for comparative morphology: simple staining methods allow highcontrast 3D imaging of diverse non-mineralized animal tissues. BMC Physiology 9:11.

682 DOI: $10.1186 / 1472-6793-9-11$.

Michalik P., Piacentini L., Lipke E., Ramirez M. 2013. The enigmatic Otway odd-clawed spider 684 (Progradungula otwayensis Milledge, 1997, Gradungulidae, Araneae): Natural history, 
685

686

687

688

689

690

691

692

693

694

695

696

697

698

699

700

701

702

703

704

705

706

first description of the female and micro-computed tomography of the male palpal organ. ZooKeys 335:101-112. DOI: 10.3897/zookeys.335.6030.

Mitchell KJ. 2007. The Genetics of Brain Wiring: From Molecule to Mind. PLOS Biology 5:e113. DOI: 10.1371/journal.pbio.0050113.

Mizutani R., Suzuki Y. 2012. X-ray microtomography in biology. Micron 43:104-115. DOI: 10.1016/j.micron.2011.10.002.

Panel on Animal Health and Welfare. 2005. Opinion of the Scientific Panel on Animal Health and Welfare (AHAW) on a request from the Commission related to the aspects of the biology and welfare of animals used for experimental and other scientific purposes. EFSA Journal 3:292. DOI: 10.2903/j.efsa.2005.292.

O’Sullivan JDB., Behnsen J., Starborg T., MacDonald AS., Phythian-Adams AT., Else KJ., Cruickshank SM., Withers PJ. 2017. X-ray micro-computed tomography ( $\mu \mathrm{CT})$ : an emerging opportunity in parasite imaging. Parasitology:1-7. DOI:

$10.1017 / \mathrm{s} 0031182017002074$.

Ott SR. 2008. Confocal microscopy in large insect brains: Zinc-formaldehyde fixation improves synapsin immunostaining and preservation of morphology in whole-mounts. Journal of Neuroscience Methods 172:220-230. DOI: 10.1016/j.jneumeth.2008.04.031.

Ott SR., Elphick MR. 2003. New Techniques for Whole-mount NADPH-diaphorase Histochemistry Demonstrated in Insect Ganglia. Journal of Histochemistry \& Cytochemistry 51:523-532. DOI: 10.1177/002215540305100414.

Platt KA., Oliver MJ., Thomson WW. 1997. Importance of the Fixative for Reliable Ultrastructural Preservation of Poikilohydric Plant Tissues. Observations on Dry, 

80:599-610. DOI: 10.1006/anbo.1997.0476.

Rasmussen KE. 1974. Fixation in aldehydes a study on the influence of the fixative, buffer, and osmolarity upon the fixation of the rat retina. Journal of Ultrastructure Research 46:87102. DOI: $10.1016 / \mathrm{S} 0022-5320(74) 80024-9$.

712

Richter S., Loesel R., Purschke G., Schmidt-Rhaesa A., Scholtz G., Stach T., Vogt L., Wanninger A., Brenneis G., Döring C., Faller S., Fritsch M., Grobe P., Heuer CM., Kaul S., Möller OS., Müller CHG., Rieger V., Rothe BH., Stegner MEJ., Harzsch S. 2010. Invertebrate neurophylogeny: suggested terms and definitions for a neuroanatomical glossary. Frontiers in Zoology 7:1-49. DOI: 10.1186/1742-9994-7-29.

Sandeman DC., Sandeman RE., Derby CD., Schmidt M. 1992. Morphology of the brain of crayfish, crabs, and spiny lobsters: a common nomenclature for homologous structures. Biological Bulletin 183:304-326. DOI: 10.2307/1542217.

Schmidt M. 2016. Malacostraca. In: Schmidt-Rhaesa A, Harzsch S, Purschke G eds. Structure \& Evolution of Invertebrate Nervous Systems. Oxford: Oxford University Press, 529-582.

Snell O. 1891. Die Abhängikeit des Hirngewichtes von dem Körpergewicht und den geistigen Fähigkeiten. Archiv für Psychiatrie und Nervenkrankheiten 23:436-446. DOI:

$$
10.1007 / \mathrm{bf0} 1843462 .
$$

Sombke A., Lipke E., Michalik P., Uhl G., Harzsch S. 2015. Potential and limitations of X-Ray micro-computed tomography in arthropod neuroanatomy: A methodological and comparative survey. Journal of Comparative Neurology 523:1281-1295. DOI: 10.1002/cne. 23741 . 
729 Steinhoff POM., Sombke A., Liedtke J., Schneider JM., Harzsch S., Uhl G. 2017. The

730 synganglion of the jumping spider Marpissa muscosa (Arachnida: Salticidae): Insights

731 from histology, immunohistochemistry and microCT analysis. Arthropod Structure \&

732 Development 46:156-170. DOI: 10.1016/j.asd.2016.11.003.

733 Tuchina O., Koczan S., Harzsch S., Rybak J., Wolff G., Strausfeld NJ., Hansson BS. 2015.

734 Central projections of antennular chemosensory and mechanosensory afferents in the

735 brain of the terrestrial hermit crab (Coenobita clypeatus; Coenobitidae, Anomura).

736 Frontiers in Neuroanatomy 9:1-13. DOI: 10.3389/fnana.2015.00094.

737 Vilpoux K., Sandeman RE., Harzsch S. 2006. Early embryonic development of the central

738 nervous system in the Australian crayfish and the Marbled crayfish (Marmorkrebs).

739 Development Genes and Evolution 216:209-223. DOI: 10.1007/s00427-005-0055-2.

740 Vogt G. 2011. Marmorkrebs: Natural crayfish clone as emerging model for various biological

741 disciplines. Journal of Biosciences 36:377-382. DOI: 10.1007/s12038-011-9070-9.

742 Ziegler A., Kunth M., Mueller S., Bock C., Pohmann R., Schröder L., Faber C., Giribet G. 2011.

743 Application of magnetic resonance imaging in zoology. Zoomorphology 130:227-254.

744 DOI: $10.1007 / \mathrm{s} 00435-011-0138-8$. 


\section{Table $\mathbf{1}$ (on next page)}

Corrected voxelsizes for CLSM-datasets provided at MorphDBase.

All uploaded datasets lost their original (anisotropic) voxelsize due to conversion of the file format. Note that the voxelsizes given for $x / y$-axes resulted due to slightly varying optical zooming whereas those for the $z$-axis were modified by using the correction factor for refractive mismatch in methyl salicylate as immersion medium. Use these voxelsizes to display all cLSM-datasets provided at MorphDBase in the correct spatial scaling. 


\begin{tabular}{l|l|c|c} 
Method_Fixation & MDB identifier & x/y-voxelsize & z-voxelsize \\
\hline CLSM_Znfa & M64-001.1 & 0.702 & 1.581 \\
CLSM_Znfa & M65-001.1 & 0.8 & 1.581 \\
CLSM_Znfa & M67-001.1 & 0.703 & 1.581 \\
CLSM_Znfa & M68-001.1 & 0.84 & 1.581 \\
CLSM_Znfa & M69-001.1 & 0.876 & 1.581 \\
CLSM_Znfa & M70-001.1 & 0.767 & 1.581 \\
CLSM_Znfa & M66-001.1 & 0.881 & 1.581 \\
CLSM_Glut & M58-001.1 & 0.722 & 1.581 \\
CLSM_Glut & M59-001.1 & 0.868 & 1.581 \\
CLSM_Glut & M60-001.1 & 0.868 & 1.581 \\
cLSM_Glut & M61-001.1 & 0.737 & 1.581 \\
cLSM_Glut & M62-001.1 & 0.682 & 1.581 \\
cLSM_Glut & M63-001.1 & 0.755 & 1.581
\end{tabular}




\section{Table 2 (on next page)}

Neuronal volumes in P. fallax cf. virginalis according to the method applied.

Note that corrected volumes use a z-axial correction factor of 1.581 to minimize refractive mismatch due to scanning in methyl salicylate. Abbreviations: $D C L$, deutocerebral chemosensory lobe; AcN, accessory neuropil (lobe). 
1

\begin{tabular}{|c|c|c|c|c|c|c|c|c|c|c|c|c|}
\hline $\begin{array}{l}\text { Method_ } \\
\text { Fixation }\end{array}$ & $\begin{array}{c}\text { Stack } \\
\text { ID }\end{array}$ & $\underset{\left[\mu \mathrm{m}^{3}\right]}{\mathrm{DCL} R}$ & $\begin{array}{c}\text { DCL_R } \\
\text { corrected } \\
{\left[\mu \mathrm{m}^{3}\right]}\end{array}$ & $\begin{array}{c}\mathrm{DCL} L_{-} \mathrm{L} \\
{\left[\mu \mathrm{m}^{3}\right]}\end{array}$ & $\begin{array}{c}\text { DCL_L } \\
\text { corrected } \\
{\left[\mu \mathrm{m}^{3}\right]}\end{array}$ & $\underset{\left[\mu \mathrm{m}^{3}\right]}{\mathrm{AcN} R}$ & $\begin{array}{c}\text { AcN_R } \\
\text { corrected } \\
{\left[\mu^{3}\right]}\end{array}$ & $\underset{\left[\mu \mathrm{m}^{3}\right]}{\mathrm{AcN} L}$ & $\begin{array}{c}\text { AcN_L } \\
\text { corrected } \\
{\left[\mu \mathrm{m}^{3}\right]}\end{array}$ & $\begin{array}{c}\text { Central } \\
\text { Brain } \\
{\left[\mu m^{3}\right]}\end{array}$ & $\begin{array}{c}\text { Central } \\
\text { Brain } \\
\text { corrected } \\
{\left[\mathrm{mm}^{3}\right]}\end{array}$ & MorphDBase-ID \\
\hline$\mu \mathrm{CT}$ _Bouin & 1 & $1,486,000$ & & $1,576,000$ & & $3,646,000$ & & $3,667,000$ & & $27,713,000$ & & J_Krieger_20170807-M-53-001.1 \\
\hline$\mu C T$ Bouin & 2 & $1,699,000$ & & $1,600,000$ & & $4,129,000$ & & $4,649,000$ & & $32,730,000$ & & J_Krieger_20170807-M-51-001.1 \\
\hline$\mu C T$ Bouin & 3 & $1,555,000$ & & $1,388,000$ & & $3,789,000$ & & $3,417,000$ & & $27,083,000$ & & J_Krieger_20170807-M-52-001.1 \\
\hline$\mu C T$ BBouin & 4 & $1,274,000$ & & $1,274,000$ & & $2,942,000$ & & $2,896,000$ & & $23,533,000$ & & J_Krieger_20170807-M-54-001.1 \\
\hline$\mu C T$ CBouin & 5 & $1,515,000$ & & $1,389,000$ & & $4,809,000$ & & $3,955,000$ & & $29,820,000$ & & J_Krieger_20170807-M-55-001.1 \\
\hline$\mu C T$ CBouin & 6 & $1,585,000$ & & $1,554,000$ & & $4,292,000$ & & $3,990,000$ & & $29,373,000$ & & J_Krieger_20170807-M-56-001.1 \\
\hline$\mu \mathrm{CT}$ BBouin & 7 & $1,171,000$ & & $1,171,000$ & & $2,646,000$ & & $2,696,000$ & & $21,071,000$ & & J_Krieger_20170807-M-57-001.1 \\
\hline cLSM_Glut & 1 & 791,003 & 948,874 & 883,588 & $1,059,936$ & $1,907,300$ & $2,287,963$ & $2,010,832$ & $2,412,159$ & $17,744,962$ & $21,286,542$ & J_Krieger_20170807-M-58-001.1 \\
\hline cLSM_Glut & 2 & $1,041,729$ & $1,249,638$ & 921,645 & $1,105,587$ & $2,635,866$ & $3,161,934$ & $2,220,232$ & $2,663,347$ & $19,201,752$ & $23,034,055$ & J_Krieger_20170807-M-59-001.1 \\
\hline cLSM_Glut & 3 & 984,659 & $1,181,176$ & $1,141,834$ & $1,369,721$ & $2,680,336$ & $3,215,275$ & $2,665,802$ & $3,197,841$ & $19,883,410$ & $23,851,759$ & J_Krieger_20170807-M-60-001.1 \\
\hline cLSM_Glut & 4 & $1,094,224$ & $1,312,612$ & $1,250,843$ & $1,500,489$ & $3,309,123$ & $3,969,565$ & $3,303,236$ & $3,962,502$ & $27,828,492$ & $33,382,528$ & J_Krieger_20170807-M-61-001.1 \\
\hline cLSM_Glut & 5 & $1,119,395$ & $1,342,806$ & $1,091,079$ & $1,308,838$ & $2,581,602$ & $3,096,842$ & $2,919,363$ & $3,502,015$ & $21,709,594$ & $26,042,433$ & J_Krieger_20170807-M-62-001.1 \\
\hline CLSM_Glut & 6 & $1,084,137$ & $1,300,512$ & $1,246,876$ & $1,495,731$ & $2,430,375$ & $2,915,435$ & $2,719,847$ & $3,262,680$ & $20,655,140$ & $24,777,541$ & J_Krieger_20170807-M-63-001.1 \\
\hline cLSM_ZnFA & 1 & 817,084 & 980,155 & 619,376 & 742,989 & $2,226,071$ & $2,670,344$ & $1,165,159$ & $1,397,698$ & $18,915,004$ & $22,690,055$ & J_Krieger_20170807-M-64-001.1 \\
\hline cLSM_ZnFA & 2 & $1,343,450$ & $1,611,573$ & $1,111,938$ & $1,333,857$ & $2,760,117$ & $3,310,976$ & $2,425,304$ & $2,909,342$ & $25,255,030$ & $30,295,377$ & J_Krieger_20170807-M-65-001.1 \\
\hline cLSM_ZnFA & 3 & $1,419,327$ & $1,070,987$ & 892,802 & $1,702,596$ & $3,115,787$ & $3,172,392$ & $2,644,587$ & $3,737,634$ & $25,096,024$ & $30,104,705$ & J_Krieger_20170807-M-66-001.1 \\
\hline cLSM_ZnFA & 4 & $1,198,716$ & $1,437,957$ & $1,161,789$ & $1,393,660$ & $2,756,689$ & $3,306,871$ & $2,440,600$ & $2,927,697$ & $23,043,944$ & $27,643,055$ & J_Krieger_20170807-M-67-001.1 \\
\hline cLSM_ZnFA & 5 & $1,411,353$ & $1,693,029$ & $1,474,522$ & $1,768,805$ & $3,355,852$ & $4,025,608$ & $3,589,474$ & $4,305,856$ & $27,222,322$ & $32,655,320$ & J_Krieger_20170807-M-68-001.1 \\
\hline cLSM_ZnFA & 7 & $1,465,908$ & $1,758,472$ & $1,376,278$ & $1,650,954$ & $3,515,581$ & $4,217,219$ & $3,112,145$ & $3,733,264$ & $25,117,220$ & $30,130,071$ & J_Krieger_20170807-M-69-001.1 \\
\hline cLSM_ZnFA & 8 & 815,546 & $1,086,852$ & 906,027 & 978,312 & $2,123,881$ & $2,651,125$ & $2,210,045$ & $2,547,765$ & $15,918,198$ & $19,095,127$ & J_Krieger_20170807-M-70-001.1 \\
\hline
\end{tabular}




\section{Table 3(on next page)}

Brain volumes of six adult specimens of $P$. fallax cf. virginalis during three stages of sample preparation for $\mu \mathrm{CT}$-scanning.

Stage 1) freshly dissected brain scanned moistly in water; stage 2) after fixation in Bouin's solution but without dehydration or contrast enhancement; stage 3) after fixation, dehydration in ethanol and contrast enhancement in $2 \%$ iodine. 


\begin{tabular}{|c|c|c|c|}
\hline $\begin{array}{l}\text { Method_ } \\
\text { Fixation }\end{array}$ & $\begin{array}{c}\text { Specimen } \\
\text { ID }\end{array}$ & $\begin{array}{c}\text { Central } \\
\text { Brain }\left[\mu m^{3}\right]\end{array}$ & MorphDBase-ID \\
\hline $\mu \mathrm{CT}$ _stage_1 & 1 & $3,390,200,000$ & J_Krieger_20180329-M-71-001.1 \\
\hline $\mu$ CT_stage_2 & 1 & $3,044,452,000$ & J_Krieger_20180329-M-77-001.1 \\
\hline$\mu C T$ stage_3 & 1 & $3,224,483,000$ & J_Krieger_20180329-M-83-001.1 \\
\hline$\mu C T$ Ctage_1 & 2 & $6,524,711,000$ & J_Krieger_20180329-M-72-001.1 \\
\hline$\mu C T$ & 2 & $6,010,940,000$ & J_Krieger_20180329-M-78-001.1 \\
\hline$\mu \mathrm{CT}$ _stage_3 & 2 & $6,409,148,000$ & J_Krieger_20180329-M-84-001.1 \\
\hline$\mu \mathrm{CT}$ _stage_1 & 3 & $6,548,093,000$ & J_Krieger_20180329-M-73-001.1 \\
\hline$\mu C T$ & 3 & $5,544,624,000$ & J_Krieger_20180329-M-79-001.1 \\
\hline$\mu \mathrm{CT}$ _stage_3 & 3 & $5,022,508,000$ & J_Krieger_20180329-M-85-001.1 \\
\hline$\mu \mathrm{CT}$ _stage_1 & 4 & $7,620,066,000$ & J_Krieger_20180329-M-74-001.1 \\
\hline$\mu C T$ & 4 & $4,925,074,000$ & J_Krieger_20180329-M-80-001.1 \\
\hline$\mu C T$ & 4 & $5,451,010,000$ & J_Krieger_20180329-M-86-001.1 \\
\hline$\mu \mathrm{CT}$ stage_1 & 5 & $6,041,379,000$ & J_Krieger_20180329-M-75-001.1 \\
\hline$\mu C T$ Ctage_2 & 5 & $3,333,409,000$ & J_Krieger_20180329-M-81-001.1 \\
\hline$\mu \mathrm{CT}$ _stage_3 & 5 & $3,098,399,000$ & J_Krieger_20180329-M-87-001.1 \\
\hline$\mu C T$ Ctage_1 & 6 & $7,333,405,000$ & J_Krieger_20180329-M-76-001.1 \\
\hline$\mu C T$ stage_2 & 6 & $4,984,792,000$ & J_Krieger_20180329-M-82-001.1 \\
\hline$\mu \mathrm{CT}$ stage_3 & 6 & $5,115,247,000$ & J_Krieger_20180329-M-88-001.1 \\
\hline
\end{tabular}




\section{Table 4 (on next page)}

Average volume of deutocerebral chemosensory lobe (single lobe) of various decapod species.

Asterisks indicate resulting volumes using the correction factor for methyl salicylate provided as immersion medium by Bucher et al. (2000). 


\begin{tabular}{|c|lccl|}
\hline Taxon & Species & n & $\begin{array}{c}\text { DCL volume } \text { [mm }^{3} \text { ] } \\
\text { *with optical correction }\end{array}$ & Reference \\
\hline Astacida & Procambarus fallax cf. virginalis (juv.) & 7 & 0.0015 & this study $(\mu \mathrm{CT})$ \\
\hline Astacida & Procambarus fallax cf. virginalis (juv.) & 7 & $0.0011 / *^{*} 0.0014$ & this study (ZnFA) \\
Astacida & Procambarus fallax cf. virginalis (juv.) & 6 & $0.0011 / *^{*} 0.0013$ & this study (Karnofsky) \\
Astacida & Procambarus clarkii (adult) & 3 & 0.0097 & Beltz et al. 2003 \\
Homarida & Homarus americanus (adult) & 2 & 0.1412 & Beltz et al. 2003 \\
Anomala & Birgus latro (adult) & 1 & 0.3747 & Krieger et al. 2012 \\
Brachyura & Sesarma sp. (adult) & 3 & 0.0061 & Beltz et al. 2003 \\
\hline
\end{tabular}




\section{Figure 1}

Volumes of brain compartiments according to the methods applied.

Boxplots with median, upper and lower quartiles, minima and maxima, and outliers of volumes of the deutocerebral chemosensory lobes (DCLS) in A, the accessory lobe (AcNs) in $B$, and the central brain in C. Note that the displayed volumes for DCLs and ACNs refer to the total volumes of both brain hemispheres. All volumetric data of CLSM-scanning resulted from $z$-corrected datasets using the correction factor for refractive mismatch with methyl salicylate provided by Bucher et al. (2000). 


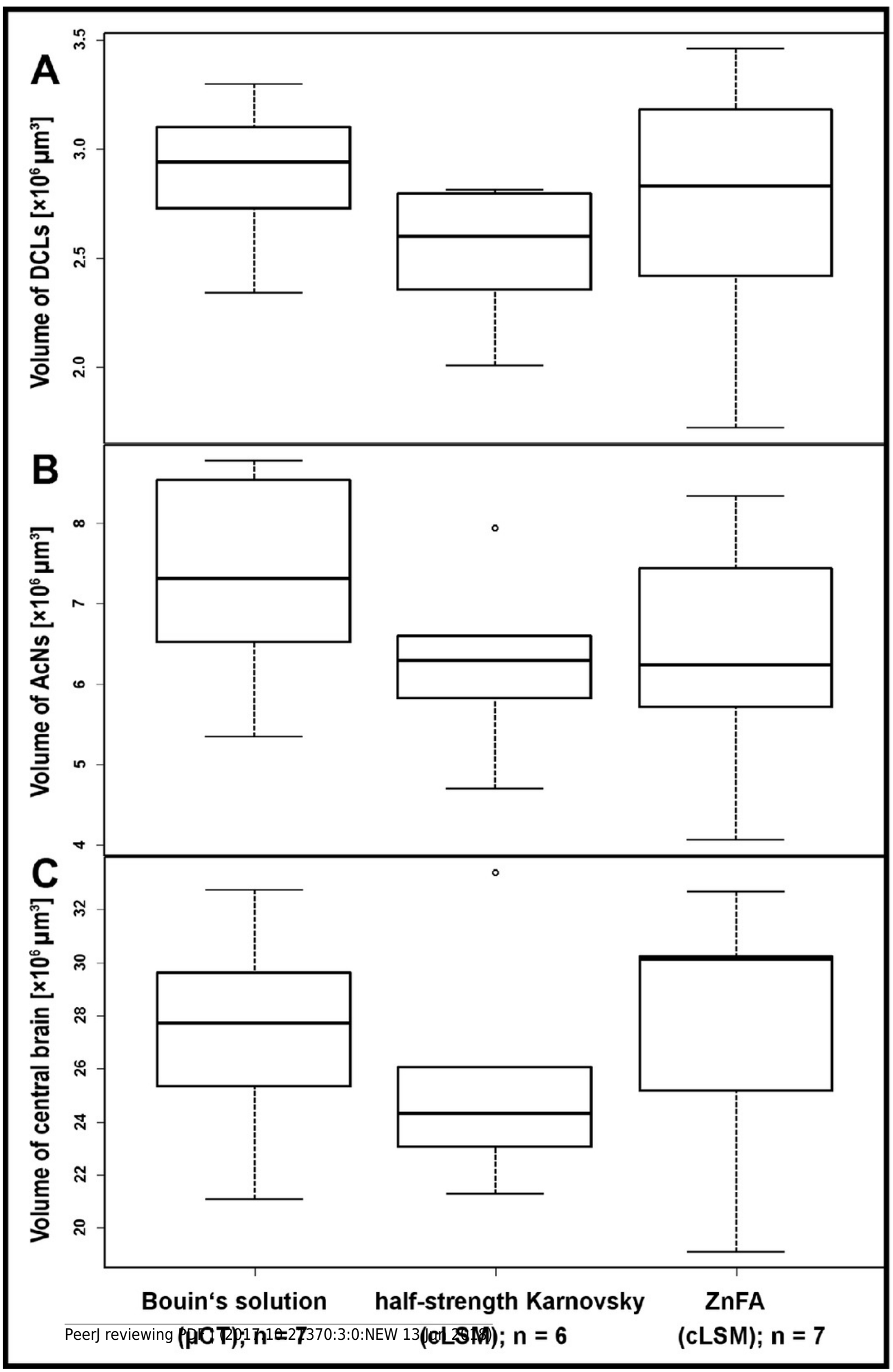




\section{Figure 2}

Comparison of volumetric data based on the methodologic approach of $P$. fallax cf. virginalis.

Each bar represents the average of reconstructed volumes of deutocerebral chemosensory lobes (DCLs), accessory lobes (ACNs), as well as of the central brain of all specimens analyzed. Note that volumes of the DCLs as well as of the AcNs are plotted pairwise (both brain hemispheres per specimen). Applied methods: $\mu \mathrm{CT}$ (Bouin-fixation), CLSM (half-strength Karnovsky's solution), and CLSM (ZnFA-fixation). The levels of significance between pairs of volumes of brain substructures according to the methods applied are based on Tukey's posthoc test from a one-way analysis of variance (ANOVA). Note that all CLSM volumes include the correction factor for refractive mismatch for methyl salicylate from Bucher et al. (2000). 


\section{Volumetric comparison of brain substructures according to the method applied}

40

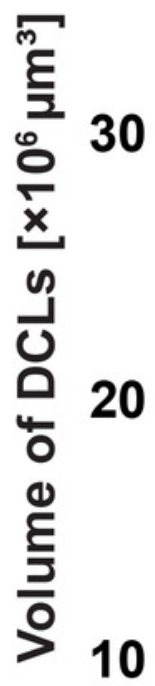

0

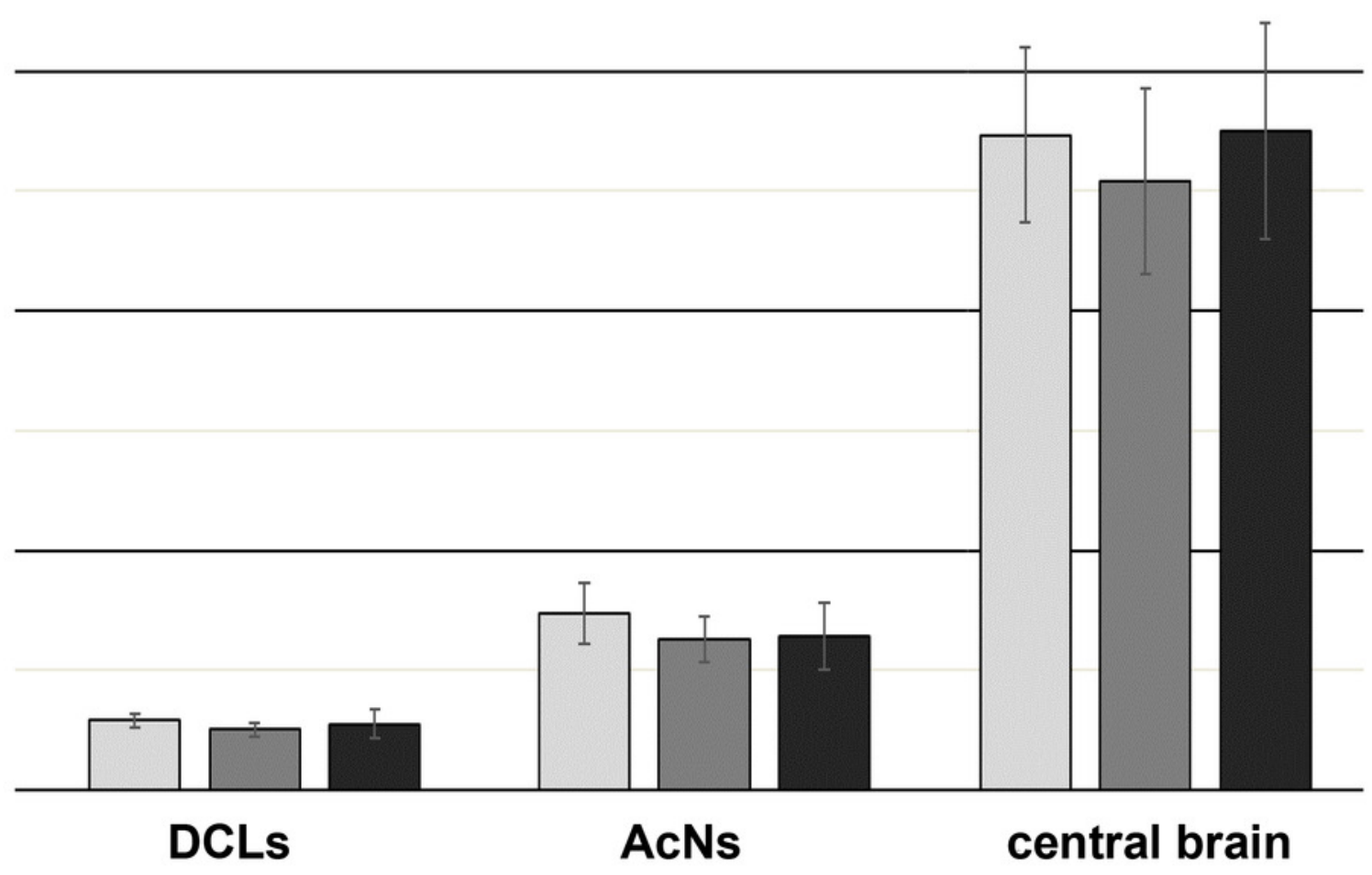

$\square$ Bouin $(\mu \mathrm{CT}) ; \mathrm{n}=7$

$\square$ half-strength Karnovsky's solution (cLSM); $n=6$

- ZnFA (cLSM); $\mathbf{n}=7$ 


\section{Figure 3}

Volume renderings of the brain in $P$. fallax cf. virginalis from a $\mu$ CT-scan.

The outline of the whole animal body is visualized in A, while in B, a virtual cutaway reveals the position of the brain (white area indicated by a black arrow) from the same perspective. The color-labeled areas in C and D are based on surface reconstruction and show the central brain (orange), the deutocerebral chemosensory lobes (DCLs: green), and the accessory lobes (AcNs: purple). Note that the lateral protocerebrum (latPC) is not reconstructed but visible in dark gray in $C$ and $D$ beneath the ommatidia of the complex-eyes (ce). Other abbreviations: Al, antenna 1 (antennule); All, antenna 2 (antenna); OC, oesophageal connective. 


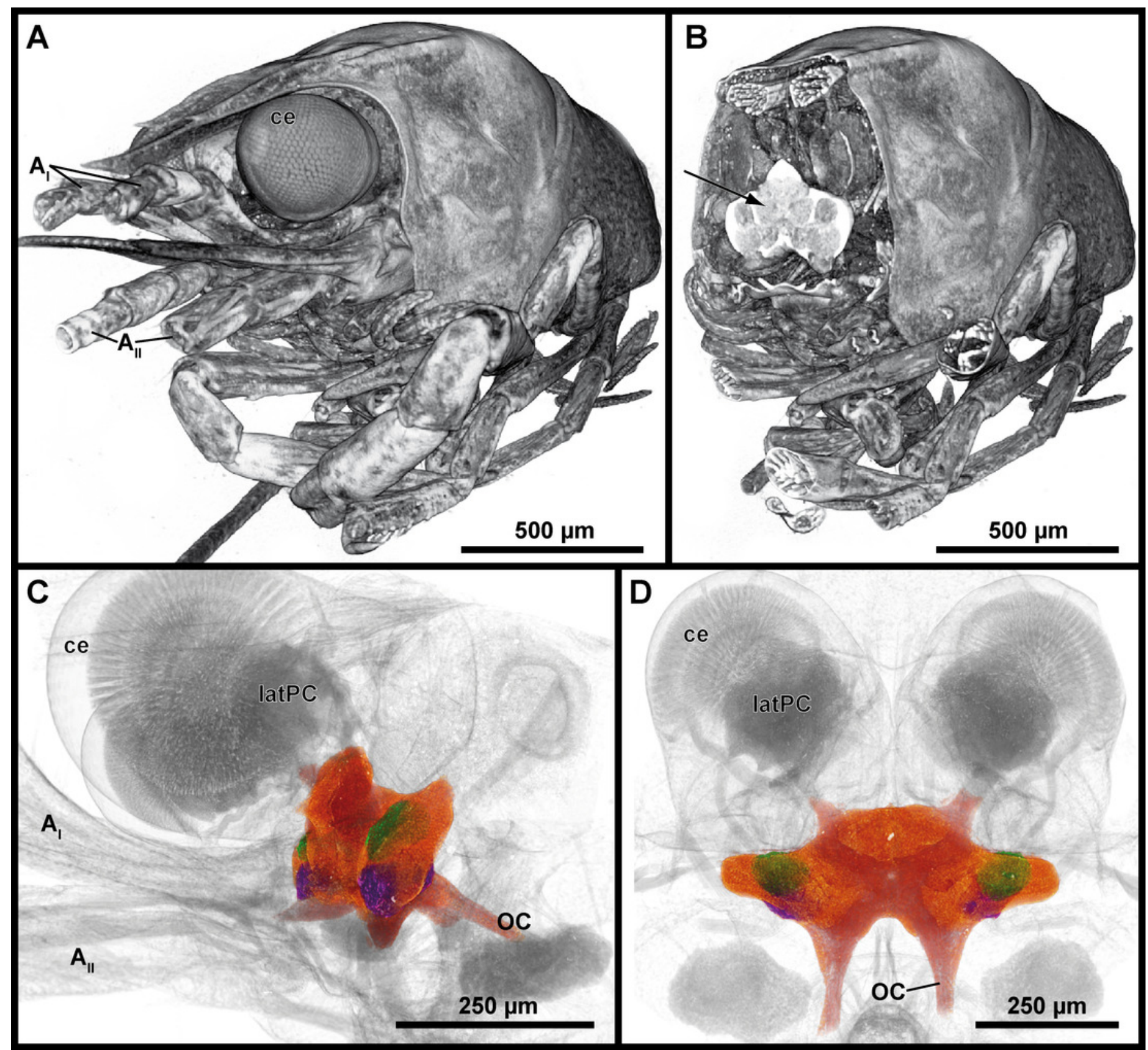




\section{Figure 4}

Comparison of virtual brain sections of $P$. fallax cf. virginalis based on all three methods applied.

The scheme in A illustrates the general organization of the central brain (omitting the lateral protocerebrum, nerves, and the oesophageal connectives). Frontal virtual sections of the central brain, according to the tomographic and corresponding fixing method applied, are shown equally scaled in B ( $\mu C T$ using Bouin's solution); in C (CLSM using autofluorescence of half-strength Karnovsky's solution); and in D (cLSM using ZnFA and immunohistochemical labeling against synapsin). Abbreviations: AcN, accessory neuropil; AMPN, anterior medial protocerebral neuropil; AnN, Antenna-II-neuropil; CA, cerebral artery; CB, central body, DCL, deutocerebral chemosensory lobe (olfactory lobe); LAN, lateral antenna-I-neuropil; MAN, median antenna-I-neuropil; PB, protocerebral bridge; PMPN, posterior medial protocerebral neuropil; PNT, projection neuron tract; TN, tegumentary neuropil; 6, 9/11, and 10 indicate somata clusters (6), (9/11), and (10); asterisk indicates olfactory glomeruli in A, C, and D. 

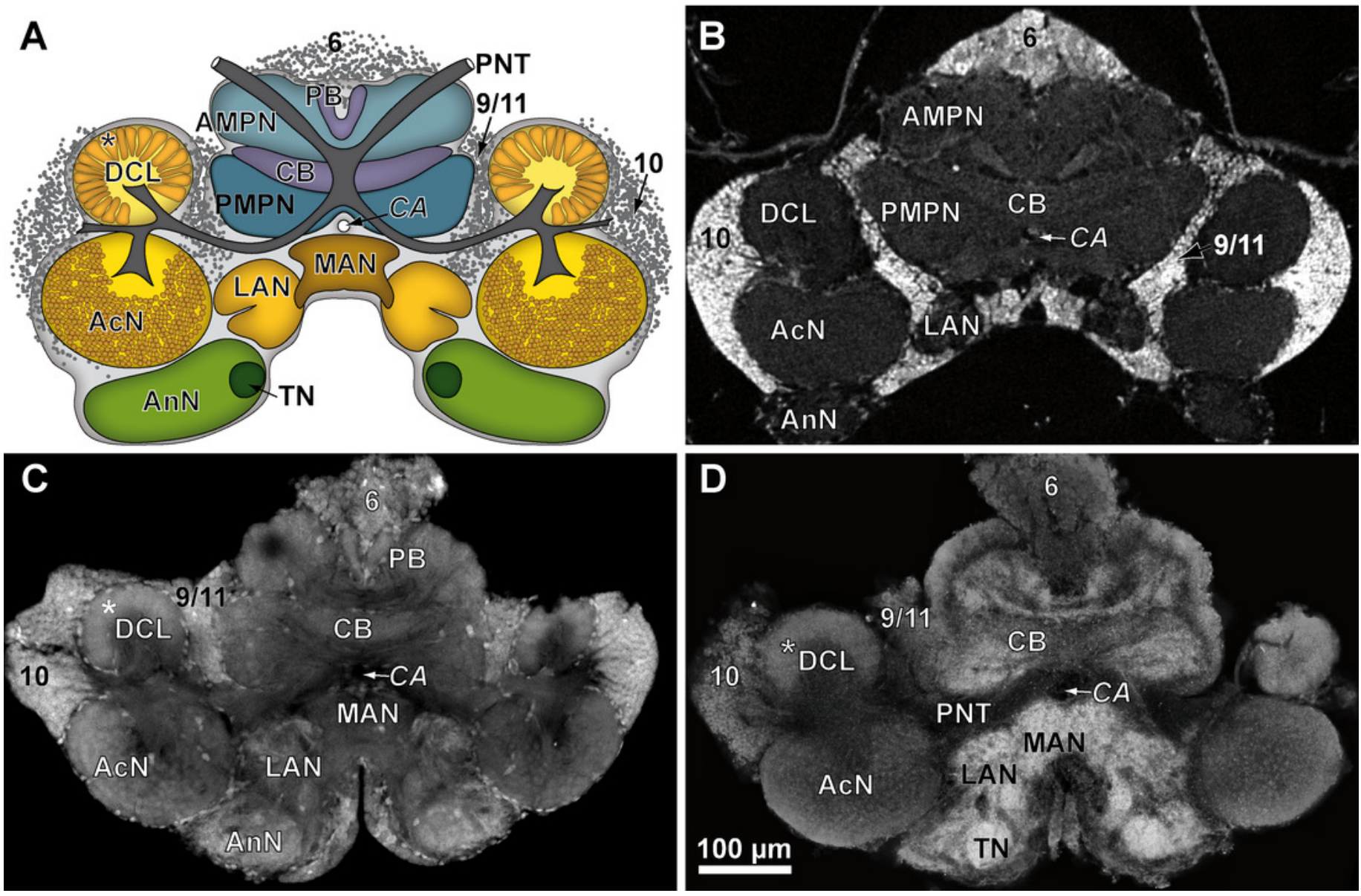


\section{Figure 5}

Virtual sections of adult individual of $P$. fallax cf. virginalis and volumes of central brains after different preparation stages.

(A) Boxplots with median, upper, and lower quartiles, minima and maxima, and outliers of volumes of the central brain after different stages of preparation for $\mu \mathrm{CT}$ wet-scanning. (B) Frontal virtual slices of the central brain of an adult individual of $P$. fallax cf. virginalis. Stage 1) The brains are just dissected and immediately scanned in tap water. Stage 2) Brains are fixed in Bouin's solution. Stage 3) Gradual dehydration and contrast enhancement with iodine (2\%) *: Significant difference between stage 1 and 2,3 (Wilcoxon signed rank test: $p=$ 0.0313; $n=6$ ) ns: No significant difference between stage 2 and 3 (Wilcoxon signed rank test: $p=0.6875 ; n=6)$. 


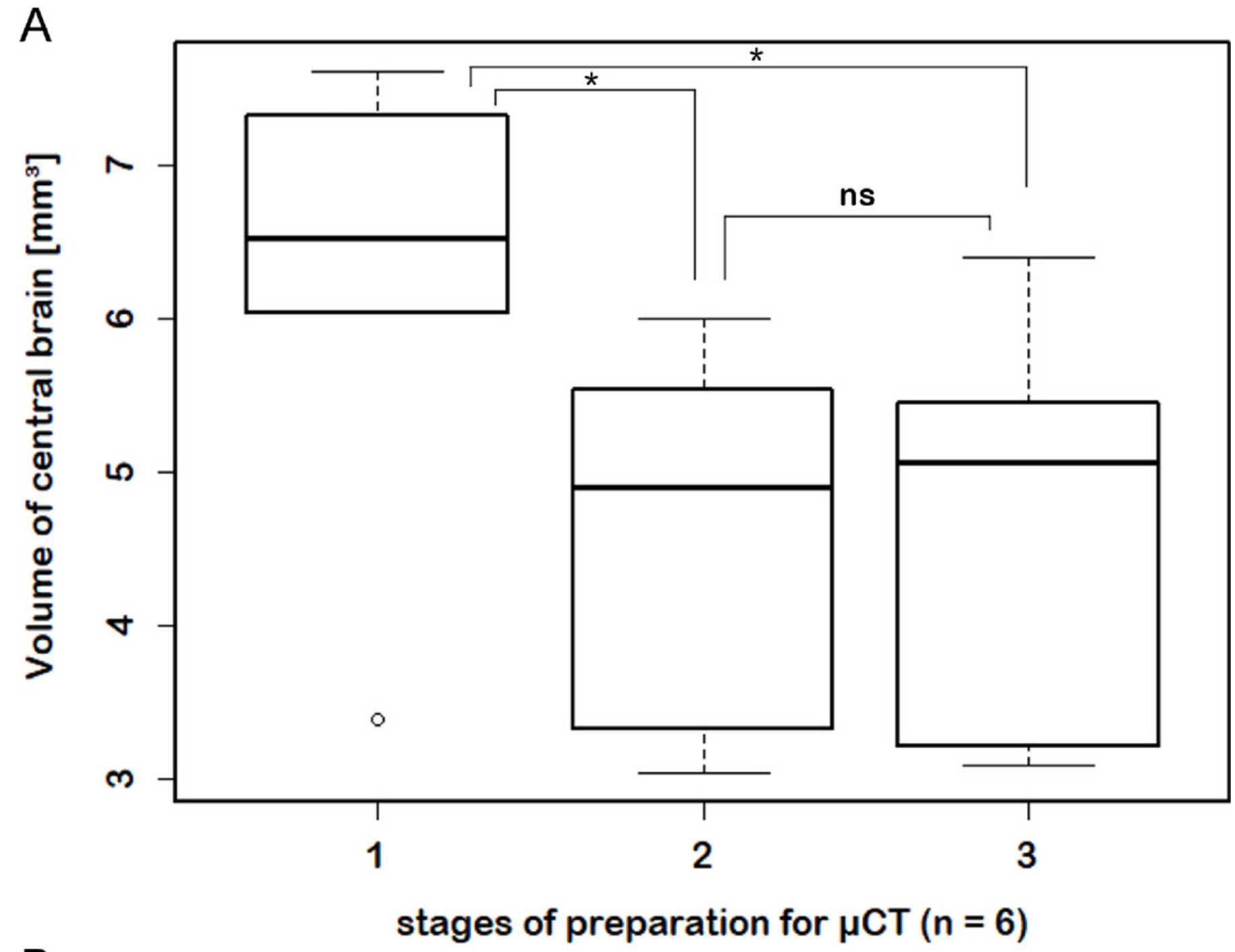

B

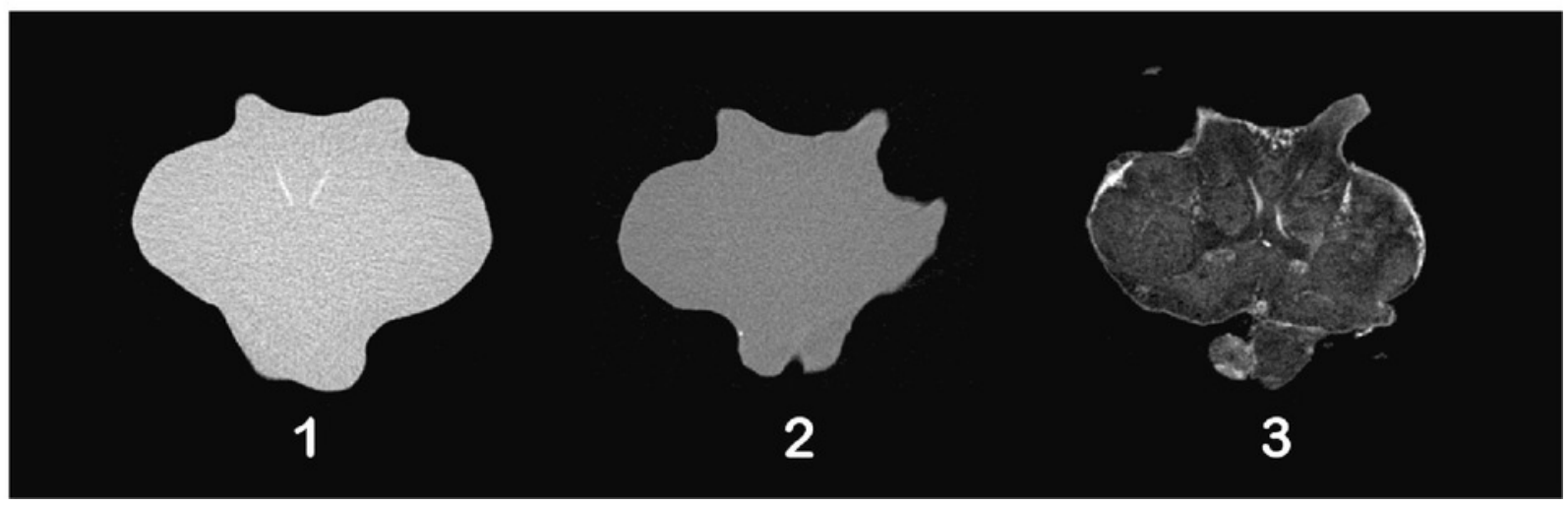




\section{Figure 6}

Comparison of grayscale-based surface reconstructions of the central brain of two individuals of $P$. fallax cf. virginalis.

The isosurfaces are based on confocal laser-scanning microscopy of dissected brains fixed in half-strength Karnovsky's solution (A-C) and in ZnFA (D-F), and are shown from different perspectives ( $A$ and $D$ : from anterioventral; $B$ and $E$ : from posteriodorsal; $C$ and $F$ : from ventrolateral). Abbreviations: AlINv, antenna 2-nerve; $\mathrm{AcN}$, accessory neuropil; $\mathrm{AnN}$, antenna 2-neuropil; DCL, deutocerebral chemosensory lobe (olfactory lobe); LAN, lateral antenna 1neuropil; mPC, median protocerebrum; OC, oesophageal connective. 


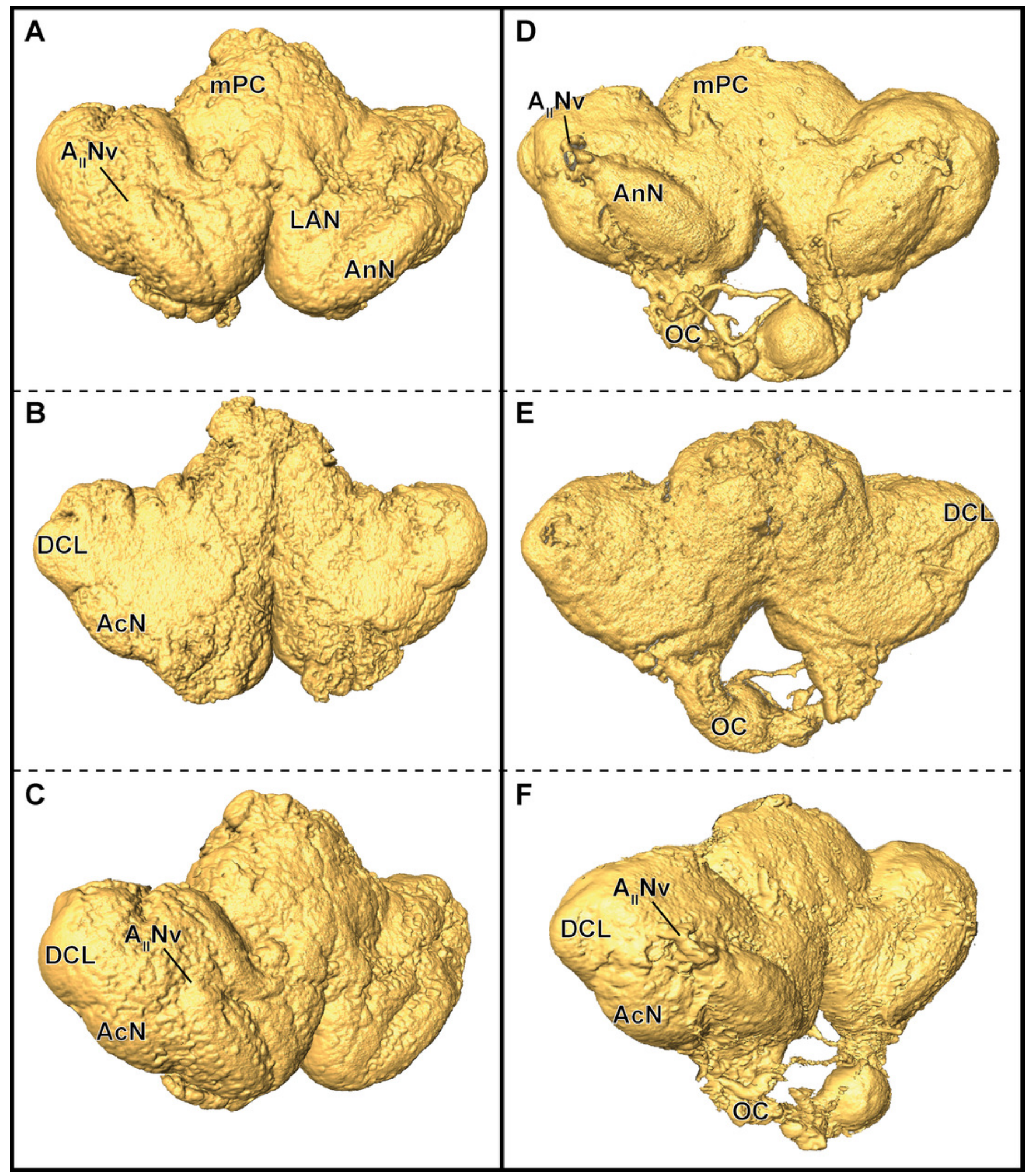

